\title{
Influence of Cell-to-Cell Variations on the Inhomogeneity of Lithium-Ion Battery Modules
}

\author{
Katharina Rumpf, $\circledast^{\mathrm{z}}$ Alexander Rheinfeld, ${ }^{*}$ Markus Schindler, Jonas Keil, Tobias Schua, \\ and Andreas Jossen
}

Institute for Electrical Energy Storage Technology (EES), Technical University of Munich (TUM), 80333 Munich, Germany

\begin{abstract}
Inhomogeneity within lithium-ion battery modules can occur due to variations in capacity and impedance of the connected cells as well as due to thermal gradients or cell connector design. We present a model for describing $x \mathrm{~S} y \mathrm{P}$ battery modules during operation, which is able to study these effects. The multidimensional multiphysics model includes a physicochemical model describing the electrochemical behavior of each cell. The electrical model accounts for the conservation of electric charge and energy between the cells to reach electrical consistency according to the respective module topology and cell interconnections. The model is capable of investigating the influence of defective and asymmetric cell connectors on the inhomogeneity of module operation. To evaluate this electrical influence, the observed inhomogeneities are compared to the influence of thermal gradients between the cells. The resulting inhomogeneous current distribution is presented for a module of two parallel connected lithium iron phosphate-graphite cells under constant current discharge operation for variations in cell capacity, cell impedance and ambient temperature at different module contact scenarios. From the observed impact of both, electrical and thermal variations between parallel connected cells, a matching strategy is derived and discussed which can enhance a module's performance during e.g. second life applications.

(C) The Author(s) 2018. Published by ECS. This is an open access article distributed under the terms of the Creative Commons Attribution 4.0 License (CC BY, http://creativecommons.org/licenses/by/4.0/), which permits unrestricted reuse of the work in any medium, provided the original work is properly cited. [DOI: 10.1149/2.0111811jes]

(cc) BY
\end{abstract}

Manuscript submitted May 16, 2018; revised manuscript received July 23, 2018. Published August 21, 2018.

New commercial lithium-ion cells show variations in capacity and impedance within a certain range due to manufacturing tolerances. ${ }^{1-5}$ When integrating unmatched cells into battery modules, these variations will lead to an inhomogeneous current distribution across the module depending on the module topology. ${ }^{6-11}$ As a consequence, the individual cells are subjected to different currents and temperatures during module operation.

The integration of unmatched cells which show variations due to manufacturing tolerances can cause inhomogeneity within battery modules. ${ }^{2,7,9,10,12,13}$ Furthermore, it can also be caused by different external reasons, for example asymmetrical cell connectors which result in uneven cell connector resistances, ${ }^{14}$ uneven ${ }^{14}$ or defective cell contacts, ${ }^{15,16}$ a disadvantageous cell arrangement, an ineffective cooling strategy ${ }^{17}$ or an external heat source next to the battery module. ${ }^{18,19}$

These external reasons lead to a thermal gradient across the battery module. ${ }^{17,18}$ On the short time scale, this gradient results in a current deviation between parallel connected cells or strings ${ }^{19}$ and therefore affects the module performance. On the long scale, temperature variations might moreover lead to differently aged cells. ${ }^{9}$

When integrating unmatched cells into battery modules, cell-tocell variations will not only lead to an inhomogeneous cell performance within the module but can also lead to local temperature peaks, which may result in selective accelerated cell aging over the time of operation.

Especially for high applied $C$-Rates unintended peak currents might approach the cell current specification limit for the assembled cells. They can become a severe safety risk, especially when occurring over a longer period of time or more often during cycle life. During charging routines of electric vehicles (EVs), high current peaks are even more severe - especially at cold ambient temperatures. ${ }^{20}$ High charging currents can then result in lithium plating, which can lead to dendrite growth and possibly to an internal short circuit in the worst case. ${ }^{20}$ Peak currents will moreover lead to a higher generated heat within the respective cell, which will increase the cell temperature and can thus lead to a thermal hotspot within the battery module. Aiming for a cell matching approach in order to reduce occurring peak currents can help to not exceed the current specification limit, reduce the generated heat and emergence of thermal hotspots and thus increase the module safety and module lifetime.
An alternative to cell matching during module assembly is to implement a balancing system within the battery management system. Whereas state of charge (SOC) balancing is state of the art and commonly used, also other balancing approaches have been reported, such as balancing the cell temperature ${ }^{21-23}$ or compensating cell terminal voltage variations due to cell-to-cell impedance differences. ${ }^{22,23}$

Effective matching during battery module assembly requires the knowledge of the varying parameters for each single cell. As related measurements are time consuming and are rarely to be realized in practice, the aim of this work is to quantify and compare the impact of manufacturing related parametric cell-to-cell variations on the evolving inhomogeneity within a battery module by simulation.

State of the art.-Prior literature studies, which have experimentally investigated the influence of connecting cells under cell-to-cell variations on the performance or aging behavior of battery modules, have been reviewed in our previous work..$^{5}$ Those studies, which have focused on modeling the effects of influencing factors on the inhomogeneity of battery modules, have mostly implemented either cell-tocell variations (in cell capacity $(d C),{ }^{6,8-11,24}$ impedance $(d R)^{6-11,22-26}$ or SOC $\left.(d S O C)^{21-23,27-29}\right)$ or thermal gradients ${ }^{19,21-23,25,27,30-33}$ or varying interconnection resistances. ${ }^{14-16,26}$ Although a comparison of the cell internal influence of both, a $d C$ and $d R$ variation is not uncommonly reported together, ${ }^{6,8-11,24}$ cell internal and cell external influences on inhomogeneity have seldom been compared. ${ }^{25-27}$ Investigations which model the inhomogeneity in battery modules have mostly used equivalent circuit models (ECMs) for the single connected cells. ${ }^{6-10,14,15,21-24,26,29-31,33}$ Only a handful of groups have used physicochemical models (PCMs) for the cells ${ }^{16,19,28,32}$ which are more demanding in terms of model parameterization and computational time compared to ECMs. However, using PCMs allows for an implementation of temperature dependent transport and kinetics parameters and moreover for a discussion from an electrochemical point of view due to a deeper insight into the electrochemical reactions during module operation. Wu et al. ${ }^{16}$ focus on the influence of cell connectors and their interconnection resistances on the performance of battery modules. Yang et al. ${ }^{19}$ and Huang et al. ${ }^{32}$ investigate the impact of thermal gradients on the current distribution between parallel connected cells. Capron et al. ${ }^{28}$ examine the impact of SOC-variation $(d S O C)$ between cells which are cooled by forced convection.

Discussing the inhomogeneity within battery module operation from an electrochemical engineering point of view poses a valuable extension of previous work in the field, which has mainly been 
focusing on aspects in electrical and mechanical engineering. Current literature is lacking a study, which is comparing different impacts on the inhomogeneity of battery modules which are either due to cell internal capacity and impedance or due to external reasons such as thermal gradients, cell connector design or defective cell contacts using the same module topology and operation scenario. A model capable of comparing these impacts, must include a holistic approach and must be able to account for all of these effects.

Originality and aim of this paper.-What becomes clear from the literature review is that - to the knowledge of the authors - current literature lacks an investigation which compares the impact of cellto-cell variations in capacity and impedance on the inhomogeneity in battery modules with that of thermal gradients and asymmetric cell connector design or defective cell contacts in one study using the same module topology and operation scenario for all influencing factors. Electric and thermal gradients across a battery module can occur simultaneously. In order to analyze their individual effects as well as their superposition, a holistic simulative investigation is sensible. Within a model environment, these effects can be readily separated which is rather challenging during experiments. For such a simulative investigation, a multiphysics coupled model is needed, which is able to account for the different influences on inhomogeneity in battery modules during operation.

Our presented work offers a model based framework including a PCM after Doyle, Fuller and Newman ${ }^{34-37}$ with temperature dependent transport and kinetics parameters for each cell. The model accounts for conservation of electric charge and energy between the cells to reach electrical consistency according to the respective module topology and cell interconnections. It is thus capable of investigating the influence of defective welding spot joints (though not shown in this paper) and asymmetric cell connectors on the module inhomogeneity, while comparing the results to those occurring due to induced thermal gradients.

For reasons of reproducibility, we provide model coupling equations for general $x \mathrm{~S} y \mathrm{P}$ battery modules in different module contact scenarios, which can be chosen from depicted flow charts.

The focus of our study is to make general statements about the evolving current distribution between connected cells under operation. Therefore, we concentrate on the most simple module topology for this purpose, namely on two parallel connected cells $(x=1$, $y=2$ ), as we think this topology is most suitable to discuss the crucial effects of different influences on inhomogeneous current distribution in battery modules. Regarding the operation scenario, we focus on constant current (CC)-discharge (DCH) at 1C. Of course, if insights into the performance of a specific battery module or system under a certain operation scenario are aimed at, then a battery module with more connected cells and more realistic load profiles are advantageous. However, as battery module topologies on the market are manifold (i.e. serial connected cells in a BMW i $3^{38}$ or highly parallelized battery systems in Tesla cars ${ }^{9}$ ), we rather aim at providing general statements using this simple battery module. Focusing on only two connected cells has the advantage that the resulting current distribution between the cells is not smeared by additional connected cells within the topology. Thereby the results can be stated very clearly and the effects by the different influencing factors can be differentiated more easily. The scalability of the resulting statements regarding larger battery systems will be evaluated in the future. The discussion results serve as a guideline for cell matching strategies during battery module assembly.

The withdrawn implications are valuable regarding second life applications of battery modules. The analyzes can give a hint on whether matching of differently aged modules with different capacities and impedances will be profitable. Exemplarily, we will present a cell matching approach in order to reduce peak currents within a $2 \mathrm{P}$ battery module.

Structure of the paper--In Influencing parameters on inhomogeneity in battery modules section, the influencing cell internal pa- rameters on cell capacity and impedance are discussed theoretically and based on literature. Typical ranges for occurring cell-to-cell variation ranges are given for capacity, impedance and ambient temperature. The development of our multidimensional multiphysics model for general $x \mathrm{~S} y \mathrm{P}$ battery modules is described in Model development section. Results and discussion section depicts the resulting inhomogeneous current distribution within a $2 \mathrm{P}$ battery module due to attributed cell-to-cell variations and different module contact designs while discussing the findings from a physicochemical point of view. To demonstrate one possible application scenario of our developed model, a matching approach for reducing peak currents during battery module operation is presented in Cell matching strategies for peak current reduction section. The cell assembly under expected thermal gradients (Assembling cells under an expected thermal gradient section) and the influence of cell connector resistances on peak currents is discussed (Influence of cell connector resistances on resulting peak currents section). From these results, implications for assembling battery modules are derived in Implications for assembling battery modules section.

\section{Influencing Parameters on Inhomogeneity in Battery Modules}

Inhomogeneity in battery modules can be influenced by cell-tocell variations and by the module design. The module design includes the choice of assembled cell connectors and the thermal management of the system. Both the cell connector resistances and evolving thermal gradients can influence the inhomogeneity in battery modules. Cell-to-cell variations in capacity and impedance are externally measurable but are contributed by multiple internal cell parameters. For the presented investigation, the respective variations in capacity and impedance across the connected cells are to be adjusted within the single cell models. Therefore, the influence of these internal parameters on both, cell capacity and cell impedance, are discussed in the following.

Influences on cell capacity.-A cell's capacity is influenced by the respective capacities of the positive and negative electrode, which are balanced according to cell design requirements. ${ }^{39}$ Based on a volumetric perspective, the capacity of a porous electrode $i$ ( $i \in$ \{neg, pos\}) calculates as follows: ${ }^{40}$

$$
C_{i}=A_{i} \cdot t_{i} \cdot \varepsilon_{\mathrm{s}, i} \cdot c_{\mathrm{s}, \max , i} \cdot\left(x_{100}-x_{0}\right) \cdot F_{\text {const }}
$$

$A_{i}\left(\mathrm{~m}^{2}\right)$ is the area of the electrode, $t_{i}(\mathrm{~m})$ is the thickness of the electrode, $\varepsilon_{\mathrm{s}, i}$ is the active material volume fraction within the electrode, $c_{\mathrm{s}, \max , i}\left(\mathrm{~mol} \mathrm{~m}^{-3}\right)$ is the theoretical maximum concentration of lithium in the active material, $\left[x_{0}, x_{100}\right] \in[0,1]$ is the range of stoichiometry during operation and $F_{\text {const }}$ is the Faraday constant. When considering the limiting electrode, a change in one of these internal parameters will change the capacity of the electrode and thus also of the lithium-ion cell.

Pre-studies have shown, that a variation of the influencing cell internal parameters has different effects.

The electrode area $A_{\text {elec, } i}$ could either vary due to the production process in case the cutting of electrodes was imprecise. Or it could decrease effectively over the cell's lifetime due to aging effects such as loss of active material. Note, that an electrode overhang area, as reported by Wilhelm et al., ${ }^{41}$ is neglected in this investigation on cell level. Moreover, $A_{\text {elec, } n e g}=A_{\text {elec, } \text { pos }}=A_{\text {elec }}$ is considered the same for both electrodes and therefore varying this parameter in the model will not change the balancing of the two electrodes to each other. As the PCM is a p2D physicochemical model, the electrode stack is modeled in 1D and within the model $A_{\text {elec }}$ does not affect the capacity of the cell.

A variation in the electrode thickness $t_{i}$ could be explained by a variation during the production process while coating the current collector with the electrode slurry or while calendering the electrode. Changing the electrode thickness $t_{i}$ in the model implies an influence on the length of electric and ionic paths through the active material and electrolyte between separator and current collector. These longer 
transport ways through the electrode result in different overpotentials and thus in different current densities.

A variation in the active material volume fraction $\varepsilon_{\mathrm{s}, i}$ could be explained by a variation during the production process while calendering the electrode. The denser the electrode is to be calendered, the higher will the active material volume fraction be compared to the fraction of electrode porosity $\varepsilon_{1}$ (which equals the volume fraction of the electrolyte). Within the model, $\varepsilon_{\mathrm{s}, i}$ influences the active specific surface area $a_{\mathrm{v}}=\frac{3 \varepsilon_{\mathrm{s}, i}}{r_{\mathrm{p}, i}}$, where $r_{\mathrm{p}, i}(\mathrm{~m})$ is the mean particle radius within the electrode (note, that spherical particles are assumed in the model). $a_{\mathrm{v}}$ influences the local current source $i_{\mathrm{v}}$, the polarization $\eta$ and thus finally, the local current density $j_{\text {loc }}$ within the electrode.

The theoretical maximum concentration of lithium in the active material of an electrode $c_{\mathrm{s}, \max , i}$ is a material parameter. It calculates from the volumetric theoretical capacity of an electrode and depends on the density of the active material $\varrho_{\mathrm{AM}, i}\left(\mathrm{~kg} \mathrm{~m}^{-3}\right)$ and its molar mass $M_{i}\left(\mathrm{~g} \mathrm{~mol}^{-1}\right)$.

$$
c_{\mathrm{s}, \max , i}=\frac{c_{\mathrm{v}, \mathrm{th}, i}}{z \cdot F_{\mathrm{const}}}=\frac{c_{\mathrm{g}, \mathrm{th}, i} \cdot \varrho_{\mathrm{AM}, i}}{z \cdot F_{\mathrm{const}}}=\frac{\varrho_{\mathrm{AM}, i}}{M_{i}}
$$

It can vary for different active material formulations. Within the model, $c_{\mathrm{s}, \max , i}$ affects the electrode kinetics during lithium intercalation by contributing to the exchange current density $j_{0}$ at the boundary between electrode particle and electrolyte. $j_{0}$ scales the local current density $j_{\text {loc }}$ in the Butler-Volmer equation within the electrode.

The stoichiometric range $\left[x_{0}, x_{100}\right]$ defines the utilization factor of the specific electrode. The electrode stoichiometry at the lithiated state of the full cell $x_{100}$ can be used to set the SOC of the electrode and thus of the full cell. It scales the initial lithium concentration $c_{\mathrm{s}, 0, i}$ within an electrode, which influences the exchange current density $j_{0}$ and the local current density $j_{\text {loc }}$. Using the electrode stoichiometry as capacity variation parameter results not only in adapting the voltage range, within which the electrode can be cycled, but also the absolute voltage level of the cell.

As the voltage level of the cell shall not be changed when implementing a cell capacity variation in the model, the internal parameter $\varepsilon_{\mathrm{s}, \text { neg }}$ is used for simulation.

Influences on cell impedance.-Different authors have investigated the influence of cell internal parameters on the cell's impedance at different time constants. ${ }^{42-50}$

The impedance of a lithium-ion cell is contributed by both electrodes $(i \in\{$ neg, pos $\})$ due to the electrode thickness $t_{i}$, the specific surface area of the electrode's porous material $a_{\mathrm{v}, i}$, the solid phase electric and liquid phase ionic conductivity $\sigma_{\mathrm{s}, i}$ and $\kappa_{1}$, and the diffusion coefficient of the salt in the liquid phase $D_{1} \cdot{ }^{45-47}$ The latter three parameters are to be corrected by the respective porous electrode's tortuosity $\tau_{i}$. Additionally, also the internal contact resistances between current collectors and active materials ${ }^{47}$ as well as the impedances of the current collectors as such ${ }^{50}$ influence the cell impedance. Reimers et al. ${ }^{50}$ have developed an equation to calculate this latter impedance $R_{\text {foil }}$, which depends on the respective tab arrangement and length $x_{\text {elec }}$ of the electrode stack design, as well as on the specific electric resistances of the current collectors $R_{\text {coll, neg }}$ and $R_{\text {coll,pos }}$ (compare Equation 22).

All of these different contributions to the cell impedance are active within different frequency ranges as their related electrochemical processes have different time constants. Our previous experimental investigation of parametric cell-to-cell variations ${ }^{5}$ has shown, that the ohmic alternating current (AC) impedances have been able to depict a statistic group building in a batch of production fresh cells, whereas the direct current (DC) impedances with time constants of $10 \mathrm{~s}$ to $60 \mathrm{~s}$ have not. Therefore, in the simulative investigation presented in this paper, a variation in the cell impedance is to be adapted using an ohmic impedance within the model. For this, the internal foil resistance $R_{\text {foil }}$ is used, which makes up about $40 \%$ of the nominal cell impedance $R_{\text {cell }}=18 \mathrm{~m} \Omega($ determined at $f=1000 \mathrm{~Hz})$.
Variation range for parameters.-In our previous experimental investigation of parametric cell-to-cell variations of production fresh commercial lithium-ion cells due to manufacturing tolerances, ${ }^{5}$ we have measured variations in capacity and impedance of two batches of cells (600 and 500 cells respectively). The investigated cell was a $3 \mathrm{Ah} 26650 \mathrm{LiFePO}_{4}$-graphite cell with a nominal ohmic impedance of $R_{\text {cell }}=18 \mathrm{~m} \Omega$ (determined at $f=1000 \mathrm{~Hz}$ ). Batch B1 showed a strong group building within the variation of the ohmic cell impedance which resulted in a coefficient of variation $\sigma /\left.\mu\right|_{R_{-A C} \_ \text {Im } 0, \mathrm{~B} 1}=1.82 \%$. Here, $\sigma$ is the standard deviation around the mean $\mu$ of the respective parametric variation. The results for batch B2 had been more significant for further studies. For batch $\mathrm{B} 2$, the $\mathrm{CC}$ and constant current constant voltage (CCCV) discharge capacity, as well as ohmic cell impedance, showed a coefficient of variation $\sigma /\left.\mu\right|_{\text {C_DCH_CC,B2 }}=0.48 \%, \sigma /\left.\mu\right|_{\mathrm{C}_{\text {DDCH_CCCV,B2 }}}=0.33 \%$ and

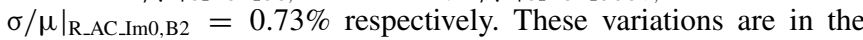
same range as those reported by Campestrini et al. ${ }^{4}$ but are smaller than those reported by other groups. ${ }^{1-3}$ Therefore and due to the possibility of group building even within a labeled batch of cells, the worst case variations within a battery module should be considered significantly higher than the measured standard deviations - even for high quality commercial cells. If a certain cell-to-cell variation is normally distributed, then $99.73 \%$ of the respective parameters lie within $\mu \pm 3 \sigma \cdot{ }^{51}$ In case cells are chosen arbitrarily from a batch of delivered cells during battery module assembly, the cell-to-cell variations can be up to $\mu \pm 3 \sigma$. Therefore, the following maximum variations around the nominal capacity and impedance of the cell are to be used during the simulative investigation in this paper. These variations are used to worsen one cell and improve the other cell within the module topology:

$$
\begin{aligned}
d C & = \pm 1.5 \%= \pm 0.045 \mathrm{Ah} \\
d R & = \pm 4.0 \%= \pm 0.72 \mathrm{~m} \Omega \\
d T & = \pm 2.5 \mathrm{~K}
\end{aligned}
$$

An absolute thermal gradient $|d T|=5 \mathrm{~K}$ is chosen for this study. This value has been reported as the maximum allowable thermal gradient within battery modules during operation. ${ }^{52,53}$

Temperature cell-to-cell variations are investigated against the background that an inefficient thermal management or an external heat source next to one side of the battery module can lead to temperature gradients across a module. ${ }^{17,18}$ This results in a current deviation between parallel connected cells or strings. ${ }^{19}$

For the cell internal model parameters the attributed variations imply a change in the active material volume fraction by $d \varepsilon_{\mathrm{s} \text {, neg }}= \pm 6.9 \times 10^{-3}$, a change in the internal foil resistance by $d R_{\text {foil }}= \pm 0.72 \mathrm{~m} \Omega$ and a change in the initial reference temperature of the cells by $d T_{\text {ref }}= \pm 2.5 \mathrm{~K}$ based on the respective values for the homogeneous system as stated in Table III and Table IV.

\section{Model Development}

The developed model of connected cells is based on the multiscale multiphysics model for single cells ${ }^{54-58}$ and consists of multiple coupled submodels (compare Figure 1). Each cell is simulated by a p2D PCM after Doyle, Fuller and Newman ${ }^{34-37}$ in order to account for the physicochemical behavior of the cell (compare (a) green box in Figure 1). On cell level, this PCM is coupled bidirectionally to a OD thermal model (THM) of the cell (compare (b) purple box in Figure 1), which in turn allows for implementing temperature dependent cell parameters within the PCM. For the electrical coupling of multiple cells, a OD electrical model (ELM) is used (compare (c) blue box in Figure 1). Regarding the thermal model of connected cells (compare (d) orange box in Figure 1), the thermal single cell model is enhanced by additionally considering the cell connectors. Furthermore, heat transfer mechanisms are implemented between cells, connectors and the surrounding air. The ELM is supplied with the total system current $i_{\text {app }}$, which is provided by the Operation model part 


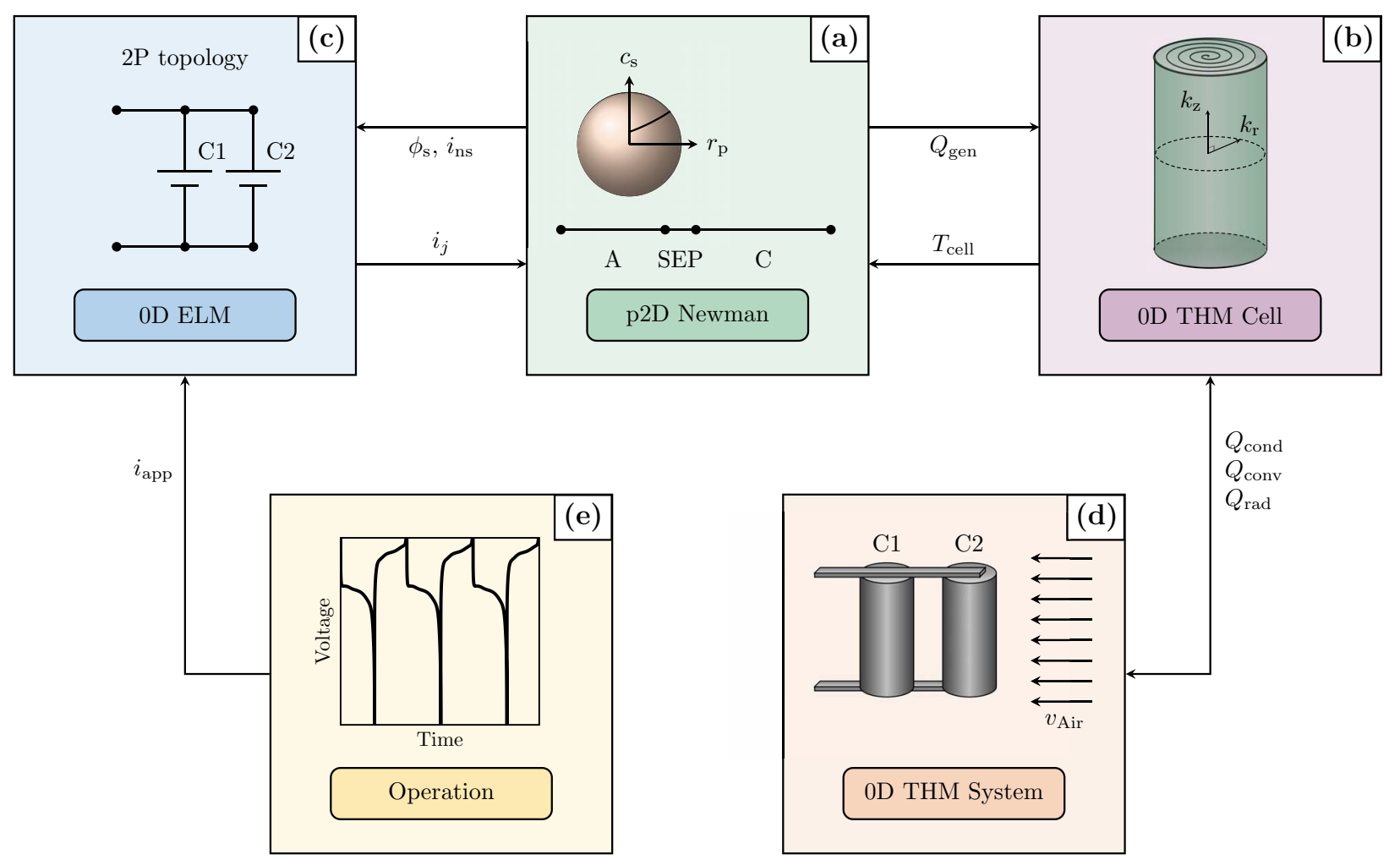

Figure 1. Scheme of the coupled model of connected lithium-ion cells: Each cell is physicochemically modeled using a p2D Newman model (PCM: (a) green box) and thermally modeled using a 0D lumped thermal model (THM Cell: (b) purple box). The generated heat $Q_{\text {gen }}$ is calculated in the PCM and coupled to the THM of the cell. In turn, the adapted cell temperature $T_{\text {cell }}$ is coupled back to the PCM. The connection of multiple cells is electrically modeled in 0D (ELM: (c) blue box) and thermally modeled in 0D (THM System: (d) orange box) by considering cell connectors, surrounding air and heat fluxes $Q_{\text {cond }}, Q_{\text {conv }}$ and $Q_{\text {rad }}$ in between. Note, that a capital $Q$ denotes that the heat fluxes have been averaged over the cell volume. The ELM is supplied with the total system current which is provided by the Operation model part ((e) yellow box).

(compare (e) yellow box in Figure 1). The presented model is built and solved in COMSOL Multiphysics 5.3a.

A cylindrical lithium-ion cell is comprised of a wound jelly roll (compare Figure 2) within a casing. The jelly roll consists of different layers. The double coated negative porous electrode material (dark gray) on a copper current collector foil (orange), followed by a separator (dashed), the double coated positive porous electrode material (green) on an aluminum current collector foil (light gray) and a second separator (dashed). The porous electrodes consist of active material particles and electrolyte filled pore volume. The inner cell stack (one anode, separator and cathode each) can be reduced to a 1D interval, which represents the whole cylindrical cell in the PCM.

Physicochemical model.-The physicochemical behavior of each single cell is described by a p2D PCM, which is based on the theory of porous electrodes and concentrated solutions and accounts for the conservation of charge and mass. The governing equations of the model are shown in Table AI in the Appendix. These equations are solved for four variables within three domains in 1D (anode, separator and cathode, which represent the whole lithium-ion cell) and within the pseudo $r$-dimension representing the active material particles. At each coordinate within both of the porous electrodes, the solid and liquid phase are assumed to exist. For the solid phase (subscript $\mathrm{s}$ ) spherical particles with particle radius $r_{\mathrm{p}}$ are modeled for both of the porous electrodes. For the liquid phase (subscript 1) the electrolyte properties are provided. The four variables, for which the equations are solved, are the electric potential of the solid phase $\left(\phi_{\mathrm{s}}\right)$ and liquid phase $\left(\phi_{1}\right)$ respectively, as well as their corresponding lithium-ion concentrations ( $c_{\mathrm{s}}$ in the particle domain and $c_{1}$ in the porous electrode domain).
Thermal model.- - The thermal behavior of each single cell is modeled using a OD THM. During operation, heat is generated within the lithium-ion cell due to different reasons, namely activation, concentration and ohmic losses. ${ }^{59}$ This heat can be calculated using the simplified Bernardi Equation: ${ }^{60}$

$$
q_{\text {gen }}=i_{\text {cell }}\left(E_{\text {eq }}-\phi_{\text {cell }}\right)-i_{\text {cell }}\left(T_{\text {cell }} \frac{\partial E_{\text {eq }}}{\partial T_{\text {cell }}}\right)
$$

$i_{\text {cell }}(\mathrm{A})$ is the cell current, $E_{\text {eq }}(\mathrm{V})$ is the open circuit potential of the cell, $\phi_{\text {cell }}(\mathrm{V})$ is the cell potential and $T_{\text {cell }}(\mathrm{K})$ is the average cell temperature. The first term describes the heat due to the cell's overpotential occurring due to ohmic losses, charge-transfer overpotentials, and mass transfer limitations, i.e. irreversible polarization heat. The second term describes the reversible part of the generated heat, i.e. entropic heat, which occurs due to a change in entropy. ${ }^{60}$

The heat which is generated by the cell is partly stored by the cell ( $q_{\text {stored }}$ in W) due to the cell's heat capacity and partly dissipated to the environment by three heat transfer processes. First, by conduction via the cell terminals ( $q_{\text {cond }}$ in W). Second, by natural or forced convection via the surrounding air $\left(q_{\text {conv }}\right.$ in $\left.\mathrm{W}\right)$. Third, by radiation $\left(q_{\mathrm{rad}}\right.$ in $\left.\mathrm{W}\right)$.

$$
\begin{gathered}
q_{\text {stored }}=m_{\text {cell }} c_{\mathrm{p}, \text { cell }} \frac{\partial T_{\text {cell }}}{\partial t} \\
q_{\text {cond }}=k_{\text {cont }} A_{\text {cont }} \frac{T_{\text {cell }}-T_{\text {cont }}}{x_{\text {cont }}} \\
q_{\text {conv }}=h_{\text {conv }} A_{\text {cell }}\left(T_{\text {cell }}-T_{\text {amb }}\right) \\
q_{\text {rad }}=\varepsilon_{\text {rad }} \sigma_{\mathrm{B}} A_{\text {cell }}\left(T_{\text {cell }}^{4}-T_{\text {amb }}^{4}\right)
\end{gathered}
$$

Here, $m_{\text {cell }}(\mathrm{kg})$ is the mass and $c_{\mathrm{p}, \text { cell }}\left(\mathrm{J} \mathrm{kg}^{-1} \mathrm{~K}^{-1}\right)$ is the specific heat capacity. $T_{\text {cont }}(\mathrm{K})$ is the temperature of the contact area 


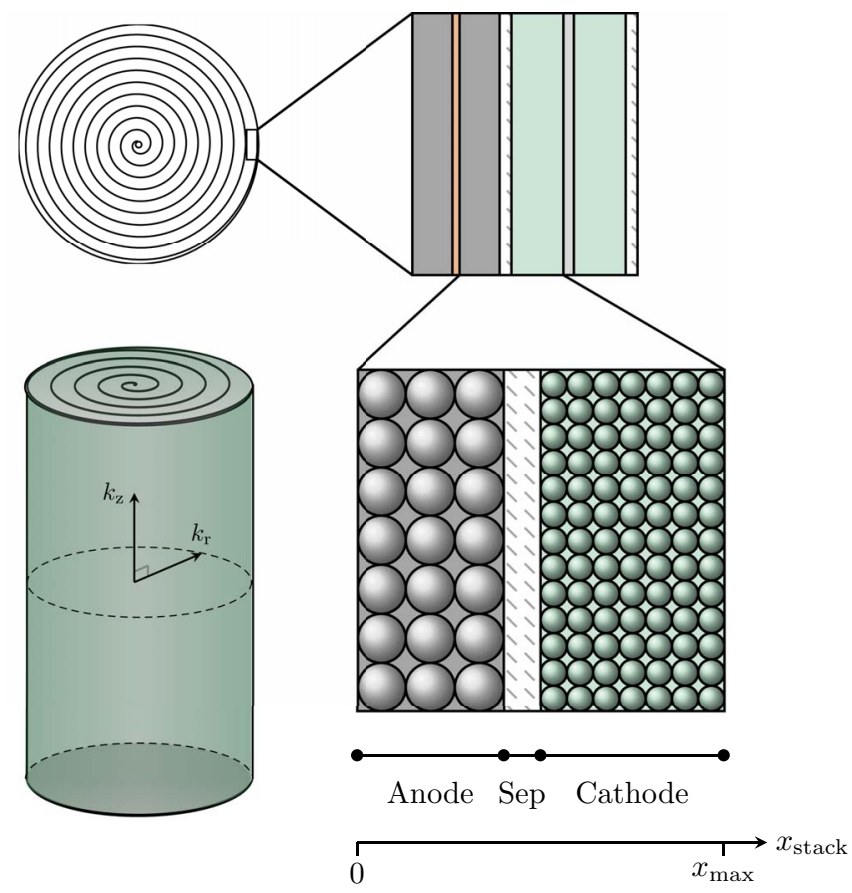

Figure 2. The jelly roll of a cylindrical cell consists of different layers: The double coated negative porous electrode material on a copper current collector foil, followed by a separator, the double coated positive porous electrode material on an aluminum current collector foil and a second separator. The porous electrodes consist of active material particles and electrolyte filled pore volume. The inner cell stack (one anode, separator and cathode each) can be reduced to a 1D interval, which represents the whole cylindrical cell in the PCM.

$A_{\text {cont }}\left(\mathrm{m}^{2}\right)$ at the cell poles, $x_{\text {cont }}(\mathrm{m})$ is the thickness of the contact area and $k_{\text {cont }}\left(\mathrm{W} \mathrm{m}^{-1} \mathrm{~K}^{-1}\right)$ is the thermal conductivity of the cell contacts. $T_{\text {amb }}(\mathrm{K})$ is the temperature of the ambient air, $A_{\text {cell }}\left(\mathrm{m}^{2}\right)$ is the surface area of the cell which is exposed to the surrounding air (strictly speaking, the portion of the surface area which is covered by the cell contacts, must not be taken into account), $h_{\text {conv }}\left(\mathrm{W} \mathrm{m}^{-2} \mathrm{~K}^{-1}\right)$ is the convective heat transfer coefficient, $\varepsilon_{\mathrm{rad}}$ is the emissivity of the cell and $\sigma_{\mathrm{B}}$ is the Stefan-Boltzmann constant.

In a lithium-ion cell, heat conduction is the only heat transport mechanism. ${ }^{37}$ Due to its layered and wound nature (compare Figure 2), a lithium-ion cell shows an anisotropic behavior regarding its thermal conductivity. The thermal conductivity across a cell stack $k_{\mathrm{r}}$ (through the layers, in case of cylindrical cells in radial direction) is one to two magnitudes smaller than the thermal conductivity along the layers of the cell stack $k_{\mathrm{z}}$ (in case of cylindrical cells in axial direction). ${ }^{61-63}$

The heat dissipation mechanisms (compare Equations 5 to 8 ) serve as boundary conditions for the energy system. In order to comply with the energy balance equation, the generated heat must equal the sum of stored and dissipated heat.

$$
\begin{aligned}
& q_{\text {gen }}=q_{\text {stored }}+q_{\text {cond }}+q_{\text {conv }}+q_{\text {rad }} \\
& i_{\text {cell }}\left(E_{\text {eq }}-\phi_{\text {cell }}\right)-i_{\text {cell }}\left(T_{\text {cell }} \frac{\partial E_{\text {eq }}}{\partial T_{\text {cell }}}\right)= \\
& +m_{\text {cell }} c_{\mathrm{p}, \text { cell }} \frac{\partial T_{\text {cell }}}{\partial t} \\
& +k_{\text {cont }} A_{\text {cont }} \frac{T_{\text {cell }}-T_{\text {cont }}}{x_{\text {cont }}} \\
& +h_{\text {conv }} A_{\text {cell }}\left(T_{\text {cell }}-T_{\text {amb }}\right) \\
& +\varepsilon_{\text {rad }} \sigma_{\mathrm{B}} A_{\text {cell }}\left(T_{\text {cell }}^{4}-T_{\text {amb }}^{4}\right)
\end{aligned}
$$

This equation is only valid if the cell can be considered having a homogeneous temperature distribution from center to surface, which means that the implementation of a lumped thermal model is justifiable. Whether this simplification can be assumed, is to be determined by calculating the Biot number Bi. Bi relates the internal heat conduction resistance $\left(r_{\text {cell }} / k_{\mathrm{r}}\right)$ to the external heat transfer resistance $\left(1 / h_{\text {conv }}\right),{ }^{64}$ where $r_{\text {cell }}$ is the radius and $k_{\mathrm{r}}$ is the radial thermal conductivity of the cylindrical cell.

$$
\mathrm{Bi}=\frac{h_{\text {conv }} r_{\text {cell }}}{k_{\mathrm{r}}}
$$

If $\mathrm{Bi}<0.1$, the cell's center temperature $T_{\text {cent }}$ and the cell's surface temperature $T_{\text {surf }}$ differ by less than $2 \%$ of the temperature difference between the cell surface temperature and the ambient temperature $\left(T_{\text {surf }}-T_{\mathrm{amb}}\right)^{65}$. For the presented 26650 cell, the Biot number calculates to $\mathrm{Bi}=0.292$, so this is a marginal case. Assuming a lumped thermal model for the cell means neglecting the cell internal temperature gradients. However, for the presented study, this simplification can be accepted due to three reasons. First, this assumption will decrease the required solving time of the model significantly compared to thermal cell models in higher dimensions. Second, under small loads as used in this paper, the temperature gradient within a cylindrical cell is reasonably small. ${ }^{66}$ Third and most important, the focus of this work is to investigate inhomogeneity within battery modules, not cells. While keeping in mind that the cell temperature will be higher in the respective cell's center than depicted in the results, the discussed gradients across the battery module and the derived principle conclusions are still valid. Therefore, a lumped thermal model is implemented, Equation 10 is used for the THM of the single cell and the anisotropic thermal conductivity within the cell is neglected. The heat related terms can thus be averaged over the volume of the cylindrical cell, which is denoted by a respective capital $Q$ in the THM.

The convective heat transfer coefficient $h_{\text {conv }}$ depends on dimensionless parameters such as Nusselt, Reynolds and Prandtl number $(\mathrm{Nu}, \mathrm{Re}, \mathrm{Pr})$ as well as on the geometry of the overflown cell or bunch of cells respectively. ${ }^{65}$ It thus defines the heat transfer to an overflowing fluid. For a single cylindrical 26650 cell $h_{\text {conv }}=22.5 \mathrm{Wm}^{-2} \mathrm{~K}^{-1}$ has been calculated for $v_{\text {air }}=1 \mathrm{~ms}^{-1}, k_{\text {air }}=0.0259 \mathrm{Wm}^{-1} \mathrm{~K}$, $\nu_{\text {air }}=1.6 \times 10^{-5} \mathrm{~m}^{2} \mathrm{~s}^{-1}, \operatorname{Pr}=0.72$ and $T=25^{\circ} \mathrm{C}$ (for the detailed calculation see the Appendix). Note, that during this investigation, each cell in the battery module is attributed the same $h_{\text {conv }}$ value. Regarding the forced convection around a bunch of cells, the fluid dynamic parameters and $h_{\text {conv }}$ change compared to those for a single cell. They are affected by the arrangement of the cylindrical cells (staggered or aligned) and by the distance between two adjacent cells. ${ }^{64}$ Especially when the influence of cell arrangements on evolving thermal gradients during operation is examined, $h_{\text {conv }}$ should be adapted for the assembled cells dependent on their respective position in the battery module. ${ }^{64}$

In a real system, connected cells will interact electrically and thermally via the cell connectors. However, we aim to investigate the pure influence of cell-to-cell variations on the module inhomogeneity and to compare the results to those when the connected cells are exposed to thermal gradients across the module. Thermal cell coupling by conduction would smear the effects of different influencing factors. This would make it harder to differentiate between and to compare the different effects. Therefore, the individual cells are considered to be at isothermal conditions throughout the conducted study. The cells are not able to interact thermally via the cell connectors but only electrically. Thermal conduction between two adjacent cells is therefore not taken into account during this study.

Electrical model.-The 0D ELM of the battery module uses the Kirchhoff circuit laws for lumped electric circuit models: (1) The sum of the currents flowing into a node equals the sum of the currents flowing out of the node (conservation of charge). Here, $n$ equals the 
number of currents around the considered node.

$$
\sum_{k=1}^{n} i_{k}=0
$$

(2) The directed sum of the electrical potential differences within any closed network is zero (conservation of energy). Here, $n$ equals the number of electric potential differences in the considered mesh.

$$
\sum_{k=1}^{n} u_{k}=0
$$

Not only the lithium-ion cells are considered in the electric model but also the electrical resistances of the cell connectors $\left(R_{\mathrm{p}}, R_{\mathrm{n}}\right)$ and welding spots $\left(R_{\mathrm{wsp}}, R_{\mathrm{wsn}}\right)$ for both, the positive and negative pole of the cell. By doing so, use cases with single defective welding spot joints and asymmetric cell connectors can be investigated. These elements need to be considered in the electric circuit model. Figure 3 depicts the different equivalent electric circuits for the respective investigated topologies.

The following assumptions are met in the model. The cell connectors are made of Hilumin (nickel plated steel), ${ }^{67}$ the distance between two adjacent cells is $d x_{\text {cell }}=5 \mathrm{~mm}$, the cell connectors are spot welded to the respective pole of the cell and four welding spots are used per cell pole. Table IV summarizes the geometric and electric data of the Hilumin cell connectors as well as the cross sectional area and corresponding electric resistance of the welding spots.

The equations of the electric model depend on the investigated module topology. Different equations apply for serial, parallel and combined cell connections and will be derived in the following.

Regardless of the topology, the current flowing into a cell $i$ at its negative pole $i_{\mathrm{n}, \text { cell }, i}$ must equal the current flowing out of the cell at its positive pole $i_{\mathrm{p}, \text { cell }, i}$ (conservation of charge) and can therefore be termed $i_{\text {cell }, i}$.

$$
i_{\mathrm{n}, \mathrm{cell}, i}=i_{\mathrm{p}, \mathrm{cell}, i}=i_{\mathrm{cell}, i}
$$

Serial connected cells.-For $x$ serial connected cells within a string $j$, the current flowing through the cells is equal and the cell potentials sum up. A string of two serial connected cells consists of the two cells, their welding spot joint resistances, their respective cell connectors and a cell connector $R_{\text {conn }}$ in between the two cells (compare Figure 3 $2 \mathrm{~S}) . i_{\mathrm{n}, j}$ denotes the current at the negative end of string $j . i_{\mathrm{p}, j}$ denotes the current at the positive end of string $j$. Based on Kirchhoff, the two currents are equal and can therefore be termed $i_{j}$.

$$
i_{\mathrm{p}, j}=i_{\mathrm{n}, j}=i_{j}
$$

As only one string of serial connected cells is considered in the $2 \mathrm{~S}$ topology, $i_{j}(j=1)$ equals the overall applied system current $i_{\text {app }}$, which is provided by the Operation module part (compare yellow box in Figure 1) and which is applied at the system terminal (ST) of the ELM.

$$
i_{j}=i_{\text {app }}
$$

These equations can be generalized for $x$ serial connected cells. For any number of $x$ serial connected cells, the respective cell currents equal the string current.

Parallel connected cells.-When considering the operation of a system of $y$ parallel connected cells, the cell current equals the string current within the respective parallel connected string $j$. In the case of the system terminal (ST) being located left of string 1 (as illustrated in Figure $32 \mathrm{P}$ for $y=2$ ), the following equations apply.

Based on the first circuit law of Kirchhoff, the current through the $j$ th string $i_{j}$ equals the difference of the applied current $i_{\text {app }}$ at the system terminal (ST) of the ELM (which is provided by the Operation module part) and the sum of currents which flow through all other parallel connected strings. Using Equation 12, the following equation
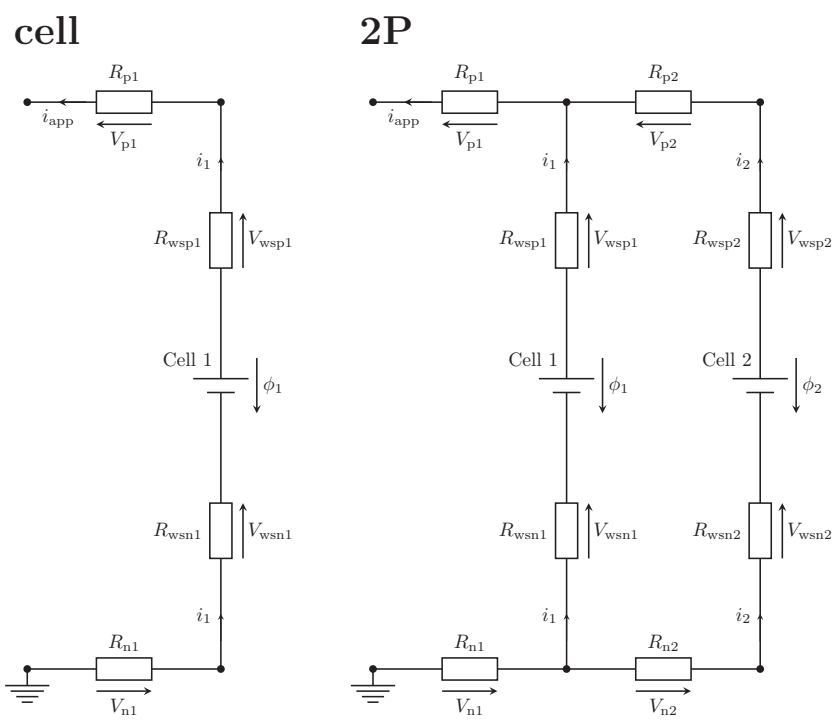

\section{$2 \mathrm{~S}$}

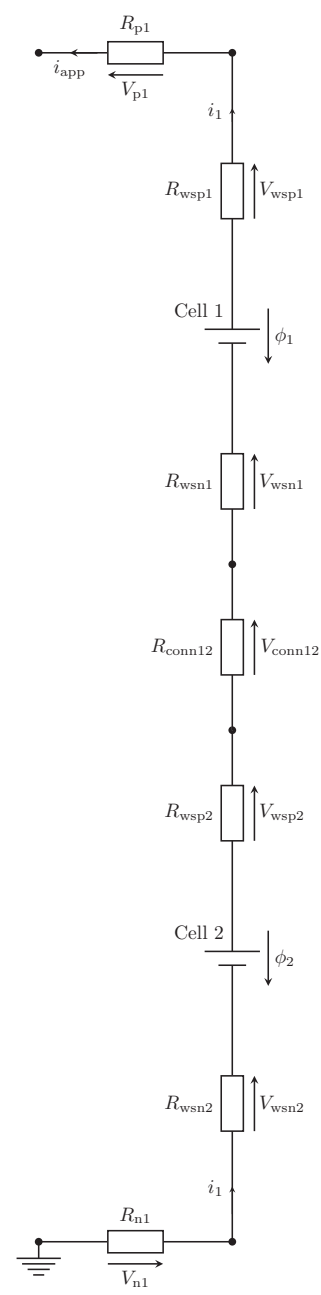

\section{S2P}

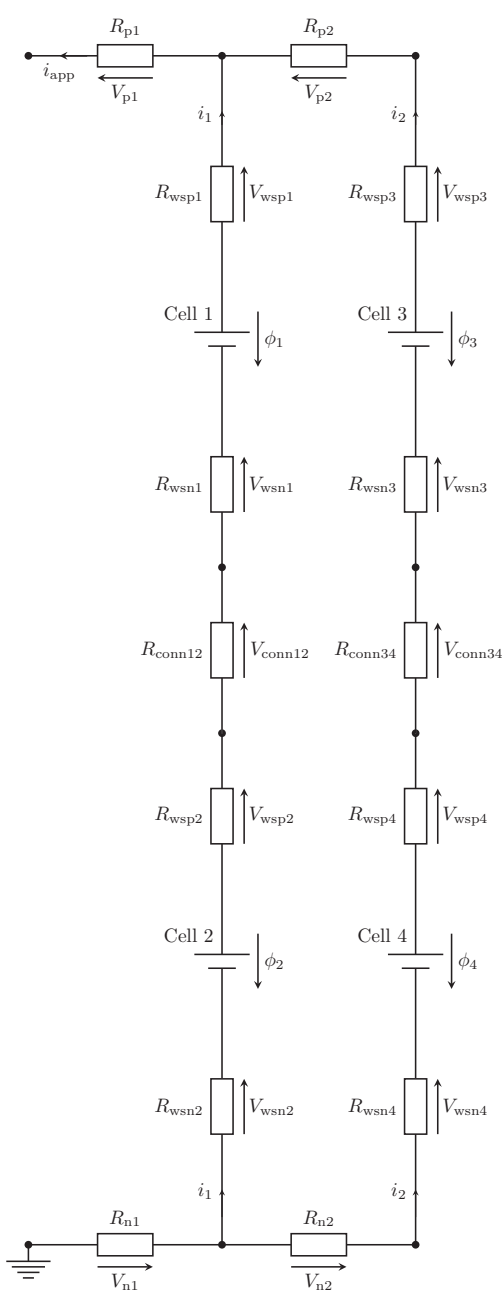

Figure 3. Equivalent electric circuits of different topologies considering both, battery cells and the resistances of cell connectors and welding spot joints. Note, that within a string of $x$ serial connected cells, the cells are numbered from top to bottom and when connected in parallel, the strings are numbered from left to right. The positive and negative connector resistances $R_{\mathrm{p}, j}$ and $R_{\mathrm{n}, j}$ are numbered according to the closest adjacent string on the right hand side of the respective connector. 
holds true for every parallel connected string $j$ :

$$
i_{j}=i_{\text {app }}-\sum_{\substack{k=1 \\ k \neq j}}^{y} i_{k}
$$

Based on the second law of Kirchhoff, the enclosed network equation can be set up considering the mesh between string 1 and string 2 , and solved for the current flowing through string 1 .

$$
i_{1}=\frac{\phi_{1}-\phi_{2}+\left(R_{\mathrm{p} 2}+R_{\mathrm{n} 2}+R_{\mathrm{wsp} 2}+R_{\mathrm{wsn} 2}\right) \cdot i_{2}}{R_{\mathrm{wsp} 1}+R_{\mathrm{wsn} 1}}
$$

This equation can be generalized for any number of $y$ parallel connected strings. However, it must be distinguished, whether the system terminal (ST) of the battery module is located at the side of the parallel connected strings (compare Figure $4 \mathrm{ST}_{\text {side }}$ ), i.e. close to string $j=1$ or $j=y$. Or, whether the ST is located somewhere in the middle of the parallel connected strings (compare Figure $4 \mathrm{ST}_{\text {mid }}$ ), i.e. in between two strings $j \in[2, y-1]$. Furthermore, the equation adapts dependent on whether the respective string is located just at the ST or further away from it, and moreover whether it is located left or right of the ST. For each of these cases a general equation for the string current $i_{j}$ is derived depending on the number of parallel connected strings $y$, resistances of cell connectors and welding spot joints. Figure $4 \mathrm{c}$ provides two flow charts (one for $\mathrm{ST}_{\text {side }}$ and one for $\mathrm{ST}_{\text {mid }}$ ) on which equation to choose according to the respective strings' position relative to the ST. Table I states these general equations (set $x=1$ for a pure parallel connection of cells), which form the base for the coupling equations between ELM and PCM (compare Model coupling section). Note, that the equations for the string currents $i_{j}$ within Table I are derived using the second law of Kirchhoff. For the remaining string currents on the right hand side of each of the equations in the table, the first law of Kirchhoff (compare Equation 17) must be used for their definition.

A $\mathrm{ST}_{\text {side }}$ connection results from a asymmetric current collector design. $\mathrm{A} \mathrm{ST}_{\text {mid }}$ connection represents a fully symmetric current collector design if only two strings are connected in parallel and if the ST is situated in the middle of the two strings. As soon as more strings are connected, the $\mathrm{ST}_{\text {mid }}$ case represents a half symmetric current collector design. To make this case fully symmetric, the ST would have to be situated at a cross position, e.g. the lower ST at the lower left end and the upper ST at the upper right end of the parallel connected strings. As investigating the influence of a disadvantageous current collector design in combination with cell-to-cell variations is more relevant, the focus of this work is on an $\mathrm{ST}_{\text {side }}$ connection. In order to compare the results to a symmetric current collector design, the current distribution within a $2 \mathrm{P}$ module is analyzed, wherefore the symmetric case can be covered by a $\mathrm{ST}_{\text {mid }}$ connection.

Combined connected cells.-For combined connected cells, $y$ strings of $x$ serial connected cells are subsequently connected in parallel. Therefore, the equations for serial and parallel connected cells must be combined. Within each of the strings $j$, still, the current at the positive end of the string $i_{\mathrm{p}, j}$ equals the current at the negative end of the string $i_{\mathrm{n}, j}$ and is therefore termed $i_{j}$ (compare Equation 15). Based on the first law of Kirchhoff, Equation 17 holds true for every parallel connected string $j \in[1, y]$. Based on the second law of Kirchhoff, the enclosed network equation can be derived considering the mesh between two adjacent strings and generalized for any number of $y$ parallel connected strings. As for the $y \mathrm{P}$ pure parallel topology, the position of the respective string relative to the ST must be considered for the $x \mathrm{~S} y \mathrm{P}$ topology. The respective flow charts for $\mathrm{ST}_{\text {side }}$ and $\mathrm{ST}_{\text {mid }}$ are depicted in Figure $4 \mathrm{c}$ and the associated equations are given in Table I. Note, that interconnections between multiple parallel strings are only considered at the top and bottom and not in the middle of the strings.

Model coupling.-The PCM and the THM of the single cell model are coupled bidirectionally. The generated heat $q_{\text {gen }}$ is integrated over
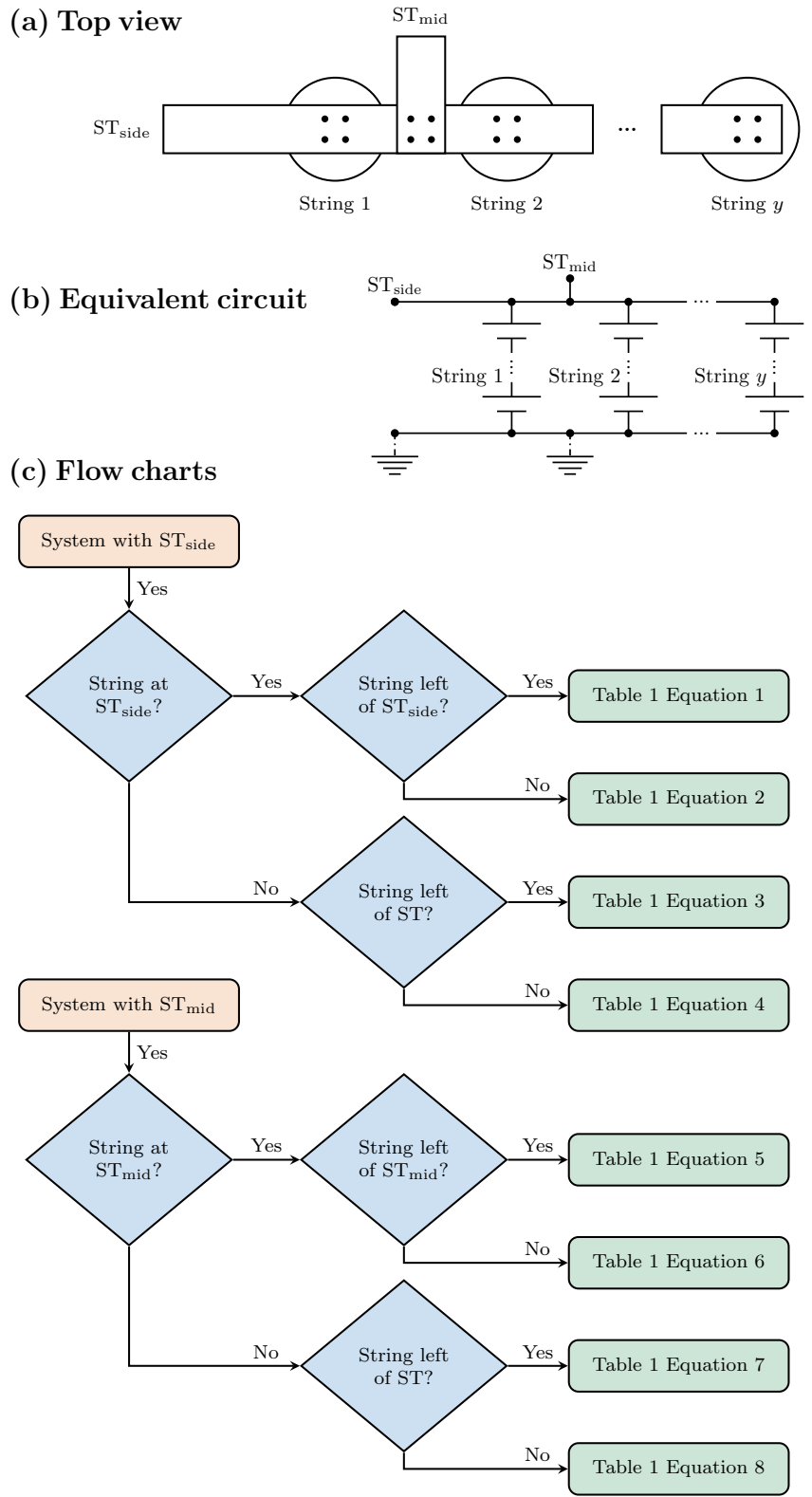

Figure 4. (a) Top view of parallel connected cells or strings. The cell connector is spot welded on the poles of the cells. The system terminal (ST) can either be located at the side $\left(\mathrm{ST}_{\text {side }}\right)$ or in the middle $\left(\mathrm{ST}_{\mathrm{mid}}\right)$ of the parallel connection. (b) Equivalent circuit of parallel connected strings illustrating the different locations of the ST. (c) Flow charts for all $x \mathrm{SyP}$ topologies about which equation in Table I to choose for determining the string current $i_{j}$ for all cells within a string $j$ according to the string position relative to the ST. Please note, that the respective flow chart needs to be run through once for each of the connected strings $j \in[1, y]$. For a pure parallel connection, set $x=1$. For a pure serial connection, set $y=1$.

the three domains of the PCM (negative electrode, separator and positive electrode) and results in $Q_{\text {gen }}$. This value is coupled into the THM as a heat source. The temperature of the cell $T_{\text {cell }}$ evolves during operation due to generated $Q_{\text {gen }}$, stored $Q_{\text {stored }}$ and dissipated heat $Q_{\text {diss }}$ (all averaged over the cell volume) according to the $0 \mathrm{D}$ energy balance equation in the THM. This adapted temperature is sequentially coupled back to the PCM. Different physicochemical parameters are implemented being temperature dependent. They adjust according to a temperature increase or decrease. The transport properties of the electrolyte $D_{1}, \kappa_{1}$ and $\frac{\partial \ln f_{ \pm}}{\partial \ln c_{1}}$ are described in dependency of lithium concentration $c_{1}$ and temperature $T_{\text {cell }}$ according to Valøen et al. ${ }^{68}$ 
Table I. General ELM equations for the string currents $i_{j}$ within $x \operatorname{S} y \mathrm{P}$ topologies, which are valid for $x \geq 1, y \geq 1$, except for 1S1P. Set $x=1$ for a pure parallel connection. Set $y=1$ for a pure serial connection. According to the decision flow charts (compare Figure 4c), the adequate equation for the desired string current $i_{j}$ can be chosen dependent on the position of the string $j$ relative to the system terminal (ST). The currents of the remaining strings on the respective right hand side of each of the equations in the table must be defined using the first law of Kirchhoff (compare Equation 17). Note, that within a string of $x$ serial connected cells, the cells are numbered from top to bottom and when connected in parallel, the strings are numbered from left to right. The positive and negative connector resistances $R_{\mathrm{p}, j}$ and $R_{\mathrm{n}, j}$ are numbered according to the closest adjacent string on the right hand side of the respective connector. Note, that the equations numbers $A$ to $G$ refer to mathematical terms which are repeated within the Equations 1 to 8.

\#

1

2

3
Equation

$i_{j}=\left(\sum_{k=(j-1) x+1}^{j x}\left(\phi_{k}\right)-\sum_{\substack{k=(j-2) x+1 \\ y>1}}^{(j-1) x}\left(\phi_{k}\right)+A+\left(R_{\mathrm{p}, j}+R_{\mathrm{n}, j}\right) \cdot \sum_{k=1}^{j-1}\left(i_{k}\right)\right) \cdot C^{-1}$

$i_{j}=\left(\sum_{k=(j-1) x+1}^{j x}\left(\phi_{k}\right)-\sum_{\substack{k=j x+1 \\ y>1}}^{(j+1) x}\left(\phi_{k}\right)+B+\left(R_{\mathrm{p},(j+1)}+R_{\mathrm{n},(j+1)}\right) \cdot \sum_{k=j+1}^{y}\left(i_{k}\right)\right) \cdot C^{-1}$

$i_{j}=\left(\sum_{k=(j-1) x+1}^{j x}\left(\phi_{k}\right)-\sum_{k=j x+1}^{(j+1) x}\left(\phi_{k}\right)+B-\left(R_{\mathrm{p},(j+1)}+R_{\mathrm{n},(j+1)}\right) \cdot \sum_{k=1}^{j-1}\left(i_{k}\right)\right) \cdot D^{-1}$

$i_{j}=\left(\sum_{k=(j-1) x+1}^{j x}\left(\phi_{k}\right)-\sum_{k=(j-2) x+1}^{(j-1) x}\left(\phi_{k}\right)+A-\left(R_{\mathrm{p}, j}+R_{\mathrm{n}, j}\right) \cdot \sum_{k=j+1}^{y}\left(i_{k}\right)\right) \cdot E^{-1}$

$i_{j}=\left(\sum_{k=(j-1) x+1}^{j x}\left(\phi_{k}\right)-\sum_{k=j x+1}^{(j+1) x}\left(\phi_{k}\right)+B+\left(\frac{R_{\mathrm{p},(j+1)}}{2}+\frac{R_{\mathrm{n},(j+1)}}{2}\right) \cdot\left(\sum_{k=j+1}^{y}\left(i_{k}\right)-\sum_{k=1}^{j-1}\left(i_{k}\right)\right)\right) \cdot F^{-1}$

$i_{j}=\left(\sum_{k=(j-1) x+1}^{j x}\left(\phi_{k}\right)-\sum_{k=(j-2) x+1}^{(j-1) x}\left(\phi_{k}\right)+A+\left(\frac{R_{\mathrm{p}, j}}{2}+\frac{R_{\mathrm{n}, j}}{2}\right) \cdot\left(\sum_{k=1}^{j-1}\left(i_{k}\right)-\sum_{k=j+1}^{y}\left(i_{k}\right)\right)\right) \cdot G^{-1}$

$i_{j}=\left(\sum_{k=(j-1) x+1}^{j x}\left(\phi_{k}\right)-\sum_{k=j x+1}^{(j+1) x}\left(\phi_{k}\right)+B-\left(R_{\mathrm{p},(j+1)}+R_{\mathrm{n},(j+1)}\right) \cdot \sum_{k=1}^{j-1}\left(i_{k}\right)\right) \cdot D^{-1}$

$i_{j}=\left(\sum_{k=(j-1) x+1}^{j x}\left(\phi_{k}\right)-\sum_{k=(j-2) x+1}^{(j-1) x}\left(\phi_{k}\right)+A-\left(R_{\mathrm{p}, j}+R_{\mathrm{n}, j}\right) \cdot \sum_{k=j+1}^{y}\left(i_{k}\right)\right) \cdot E^{-1}$

$\sum_{k=(j-2) x+1}^{(j-1) x}\left(R_{\mathrm{wsp}, k}+R_{\mathrm{wsn}, k}\right) \cdot i_{(j-1)}+\sum_{\substack{k=(j-2) x+1 \\ x>1 \\ y>1}}^{(j-1) x-1}\left(R_{\mathrm{conn},(k)(k+1)}\right) \cdot i_{(j-1)}$

$\sum_{\substack{k=j x+1 \\ y>1}}^{(j+1) x}\left(R_{\mathrm{wsp}, k}+R_{\mathrm{wsn}, k}\right) \cdot i_{(j+1)}+\sum_{\substack{k=j x+1 \\ x>1 \\ y>1}}^{(j+1) x-1}\left(R_{\mathrm{conn},(k)(k+1)}\right) \cdot i_{(j+1)}$

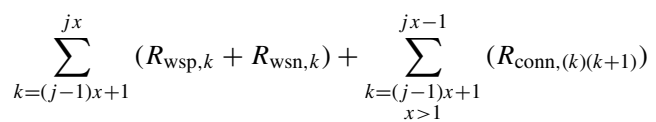

$\left(R_{\mathrm{p},(j+1)}+R_{\mathrm{n},(j+1)}\right)+C$

$\left(R_{\mathrm{p}, j}+R_{\mathrm{n}, j}\right)+C$

$\left(\frac{R_{\mathrm{p},(j+1)}}{2}+\frac{R_{\mathrm{n},(j+1)}}{2}\right)+C$

$\left(\frac{R_{\mathrm{p}, j}}{2}+\frac{R_{\mathrm{n}, j}}{2}\right)+C$ 
Table II. General coupling equations between ELM and PCM for different topologies of $x$ serial and $y$ parallel connected cells. $j$ denotes the number of that parallel connected string where the cell $i$ is located. $o$ denotes the number of strings in between string $j$ and the ST. For a pure parallel connection, the equations for $x$ SyP can be used with $x=1$.

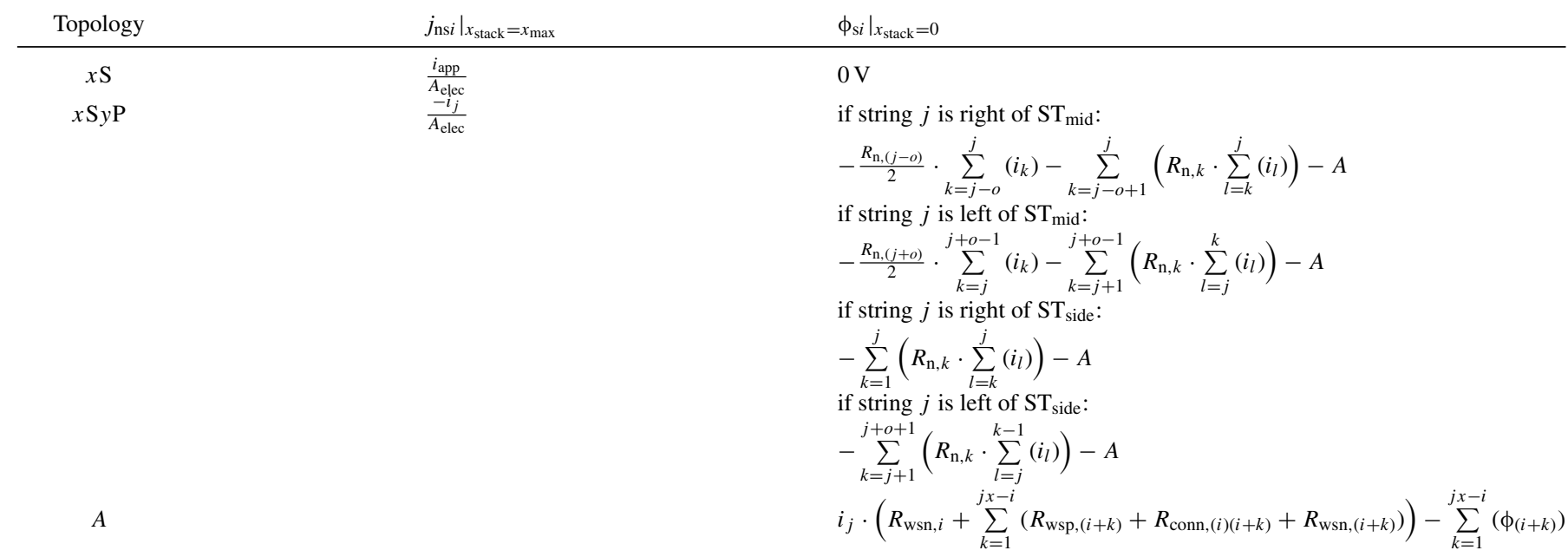

(compare appendix Equations A5 to A7). The diffusivity and reaction rate in the electrodes are assumed to follow a temperature dependent Arrhenius behavior according to Guo et al. ${ }^{69,70}$ (compare appendix Equations A8 and A9).

Regarding the coupling between PCM and ELM, two coupling relevant variables are calculated in each time step within the PCM of each cell. The cell potential difference of the solid phase between positive and negative cell pole $\phi_{\mathrm{s}}$ and the electrode current density $i_{\mathrm{ns}}$, which is normal to the $1 \mathrm{D}$ interval. The two respective variables of all connected cells $i \in[1, x \cdot y]$ are passed to the ELM.

The ELM requires the total battery system current $i_{\text {app }}$ as input for calculating the respective string currents. This system current is provided by the Operation model part (compare yellow box in Figure 1). Any desired current profile can be chosen according to the study focus. The ELM calculates the string currents $i_{j}$ for every $j$ th string from the equations in Table I. For each of the cells within a string $j$ the cell currents equal the string current. These cell currents are used within the PCM for calculating the potential boundary condition at the negative cell pole $\left.\phi_{\mathrm{si}}\right|_{x_{\text {stack }}=0} \cdot x_{\text {stack }}$ denotes the $x$-coordinate of the PCM interval (compare Figure 2). $x_{\text {stack }}=0$ denotes the interval boundary at the anode of the PCM cell stack, $x_{\text {stack }}=x_{\max }$ denotes the interval boundary at the cathode of the PCM cell stack.

Within the model, the following equations are used for each $i$ th of the $x$ serial connected cells:

$$
\begin{gathered}
\left.\phi_{\mathrm{s} i}\right|_{x_{\text {stack }}=0}=0 \mathrm{~V} \\
\left.j_{\text {ns } i}\right|_{x_{\text {stack }}=x_{\text {max }}}=\frac{i_{\text {app }}}{A_{\text {elec }}}
\end{gathered}
$$

The respective potential differences of the serial connected cells $\phi_{1}$ and $\phi_{2}$ (for a $2 \mathrm{~S}$ system), are added up to a string potential $\phi_{j}$ during each time step while subtracting the potential drops which occur at the respective cell connector $\left(R_{\mathrm{p}}, R_{\mathrm{n}}\right)$ and welding spot $\left(R_{\mathrm{wsp}}\right.$, $\left.R_{\text {wsn }}\right)$ resistances within the string. For a pure parallel connection of $y$ cells, the equations for calculating the respective cell potential at the negative cell pole vary according to the position of the cell respective to the ST. This is also true for a combined connection of $x$ serial and $y$ parallel cells. In both cases, it has to be distinguished, in which of the parallel strings $j \in[1, y]$ the respective cell $i$ is located and whether this string $j$ is located left or right of $\mathrm{ST}_{\text {side }}$ or $\mathrm{ST}_{\text {mid }}$. The equations for $\left.\phi_{\mathrm{s} i}\right|_{x_{\mathrm{stack}}=0}$ are given in Table II, where $o$ denotes the number of strings in between string $j$ and the ST. Note, that the equations which are given for $x \mathrm{~S} y \mathrm{P}$ systems can also be used for $1 \mathrm{~S} y \mathrm{P}$ systems. For the applied current density to the respective cell's PCM, the string currents $i_{j}$ with $j \in[1, y]$ are used:

$$
\left.j_{\text {nsi }}\right|_{x_{\text {stack }}=x_{\max }}=\frac{i_{j}}{A_{\text {elec }}}
$$

The electric coupling is established. The general PCM-ELM coupling equations are summarized in Table II.

Validation and parameterization.-The cell used for parametrisation of the model and the following investigations is a commercial 3.0 Ah $26650 \mathrm{LiFePO}_{4}$-graphite cell (SonyUS26650FTC1) with a nominal ohmic impedance of $R_{\text {cell }}=18 \mathrm{~m} \Omega$ (determined at $f=1000 \mathrm{~Hz}$ ). For further nominal data of the investigated cell, refer to Rumpf et al. ${ }^{5}$ In order to parameterize the single cell model, one single cell has been subjected to two measurement routines in a thermal test bench at $T_{\mathrm{amb}}=25^{\circ} \mathrm{C}$ and $v_{\mathrm{air}}=1.0 \mathrm{~ms}^{-1}$ : (Part 1) Cooling tests: $\mathrm{CC}$ pulse profiles, followed by an open circuit (OC) period and (Part 2) C-Rate tests: CC discharge tests at different CRates. For a detailed description of the custom made thermal test bench, refer to Rheinfeld et al. ${ }^{55}$ Within the thermal test bench, an air flow with a predefined velocity can be set. Using this velocity, the convective heat transfer coefficient, which occurs at the investigated cell can be calculated (compare appendix). The heat capacity of a cell can be calculated using the masses and heat capacities of the individual cell components. ${ }^{71}$ The component masses have been measured, the component heat capacities have been taken from Chen et al. ${ }^{61}$ and Guo et al. ${ }^{72}$ The calculated heat capacity of the investigated cell is $1300 \mathrm{Jkg}^{-1} \mathrm{~K}^{-1}$. This value can be used for a first simulation. The thermal parameter fitting has been performed as described by Zhang et al. ${ }^{66}$ Using the calculated heat transfer coefficient, the heat capacity of the cell can be adapted within the simulation until experimental and simulated data coincide. The final value used during the simulations in this study is $1400 \mathrm{Jkg}^{-1} \mathrm{~K}^{-1}$. This heat capacity value needs to hold true for both, the cooling tests and the rating tests.

In the first part, the cell temperature has internally been increased by pulsing the cell using different $\mathrm{CC}$ pulse profiles until the cell reached a thermally steady state $\left(Q_{\text {in }}=Q_{\text {out }}\right)$. The periodic pulse profiles have been designed using short current pulses in a way, that the mean $S O C$ of the cell has not been changed during operation.

- 1Cch-2Cdch: CC charge $I_{\mathrm{ch}, \mathrm{CC}}=1 \mathrm{C}=3 \mathrm{~A}$ for $t=2 \mathrm{~s}$ followed by a CC discharge $I_{\mathrm{dch}, \mathrm{CC}}=2 C=6 \mathrm{~A}$ for $t=1 \mathrm{~s}$ (period $\tau=3 \mathrm{~s}$ ).

- 1Cch-4Cdch: CC charge $I_{\mathrm{ch}, \mathrm{CC}}=1 \mathrm{C}=3 \mathrm{~A}$ for $t=4 \mathrm{~s}$ followed by a CC discharge $I_{\mathrm{dch}, \mathrm{CC}}=4 C=12 \mathrm{~A}$ for $t=1 \mathrm{~s}($ period $\tau=5 \mathrm{~s})$.

- 1Cch-6Cdch: CC charge $I_{\text {ch,CC }}=1 C=3 \mathrm{~A}$ for $t=6 \mathrm{~s}$ followed by a CC discharge $I_{\mathrm{dch}, \mathrm{CC}}=6 C=18 \mathrm{~A}$ for $t=1 \mathrm{~s}($ period $\tau=7 \mathrm{~s})$. 

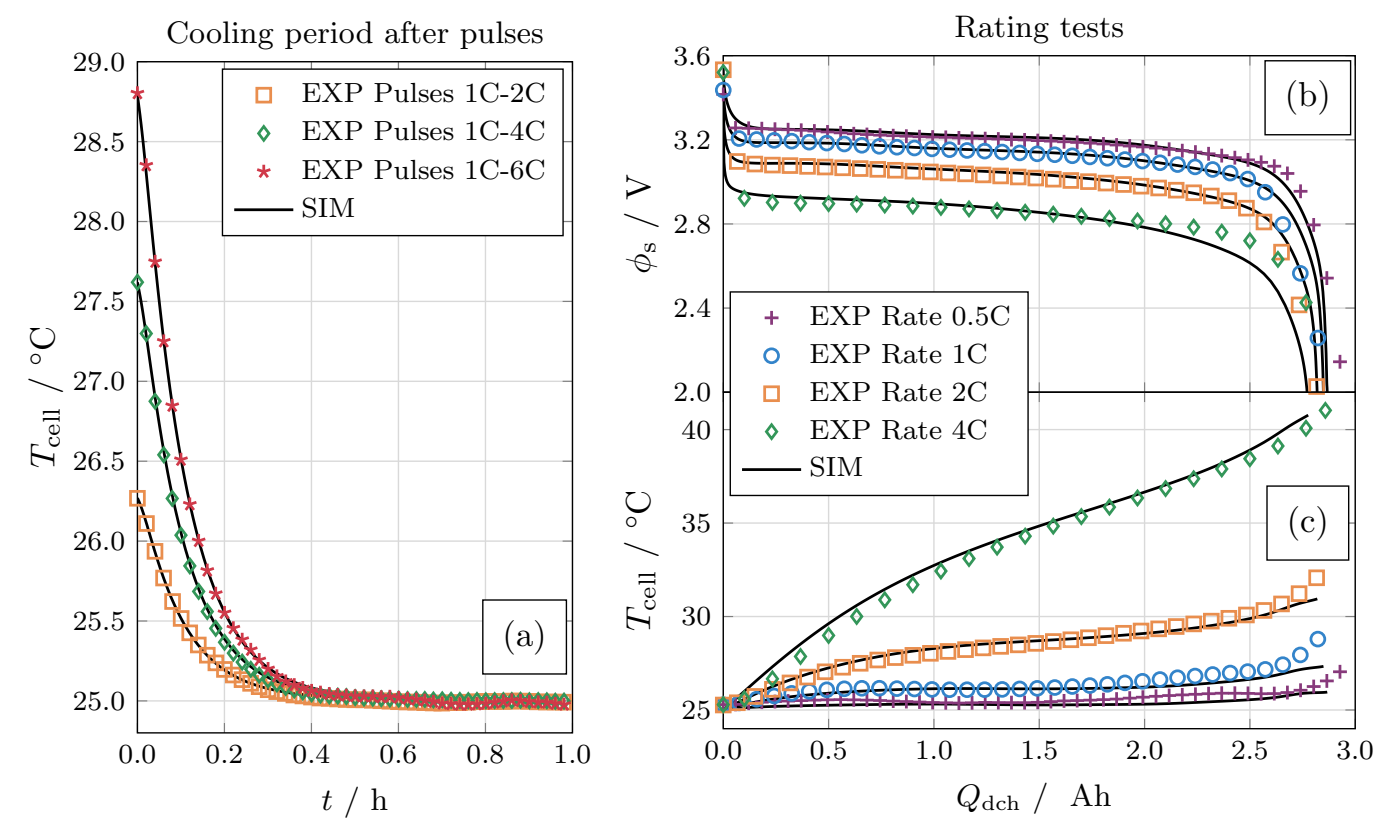

Figure 5. Validation of the single cell model at $T_{\mathrm{amb}}=25^{\circ} \mathrm{C}$ and $v_{\text {air }}=1.0 \mathrm{~ms}^{-1}$ under (a) thermally steady conditions during an OC period for the cell temperature $T_{\text {cell }}$ and under rating tests for (b) cell potential $\phi_{\mathrm{s}}$ and (c) cell temperature $T_{\text {cell }}$. The resulting model parameters are given in Table III and Table IV.

After the thermally stationary state had been reached, the respective pulse profile was followed by an OC phase of $t=1 \mathrm{~h}$. During this OC phase the cell was cooled due to the forced air convection applied in the thermal test bench at the given air velocity $v_{\text {air }}$. The thermal parameter fitting has been performed during these cooling periods. The resulting comparison between the respective measured and simulated cooling phases for $v_{\text {air }}=1 \mathrm{~ms}^{-1}$ is depicted in Figure $5 \mathrm{a}$.

In the second part, the model has been parameterized regarding the cell behavior under $\mathrm{CC}$ discharge at different C-Rates. The resulting comparison between measurement and simulation curves for both, cell potential and cell temperature, are shown in Figures $5 \mathrm{~b}$ and $5 \mathrm{c}$ respectively. The resulting model parameters are summarized in Table III and Table IV.

Within the PCM, only the electrodes and separator but not the current collectors are modeled (compare Figure 2). During parametrisation, deviations might occur regarding the measured and simulated overpotentials. As already mentioned in Influences on cell impedance section, Reimers ${ }^{50}$ has introduced a method to analytically account for the additional impedances of the current collectors which contribute to the overall impedance of a cell. He developed an equation to calculate this impedance $R_{\text {foil }}$ dependent on the respective tab arrangement of the electrode stack design. The present investigated cell has a three tab design, therefore the respective impedance calculates to

$$
R_{\text {foil }}=\frac{1}{12} x_{\text {elec }}\left(R_{\text {coll, neg }}+R_{\text {coll, pos }}\right)=6.9 \mathrm{~m} \Omega
$$

Here, $x_{\text {elec }}=140 \mathrm{~cm}$ is the length of the electrode stack. $R_{\text {coll, neg }}$ $(\Omega)$ and $R_{\text {coll,pos }}(\Omega)$ are the specific electrical resistances of the respective current collectors. The foil resistance which is fitted during parameterization of the single cell model is $R_{\text {foil }}=8 \mathrm{~m} \Omega$. The fitted value is a little higher than the calculated value due to the additional internal contact resistances inside the cell.

\section{Results and Discussion}

In a first step, the influence of cell-to-cell variations on the inhomogeneity of current distribution within a $2 \mathrm{P}$ module under different ST contact positions is investigated at $1 C$. A $1 C$ discharge of the system corresponds to a system current of $i_{\text {app }}=-6 \mathrm{~A}$. The intention is to discharge each of the cells by a cell current of $i_{1}=i_{2}=-3 \mathrm{~A}$, which again corresponds to a $1 C$ discharge on cell level. Besides of the inhomogeneous current distribution, also the resulting difference in Ah-throughput between the connected cells is discussed. Using these results, the possibility of cell matching for reducing peak currents during operation is examined. On the one hand, assembling cells with varying capacity and impedance under an expected thermal gradient is analyzed. Like this, the combination of an externally induced $d T$ variation and a cell internal $d C$ or $d R$ variation can be compared. On the other hand, the influence of the cell connector resistance on the resulting peak currents is analyzed. Based on the results, five implications for assembling battery modules are derived.

Inhomogeneous current distribution due to cell-to-cell variations.-In order to examine the influence of cell-to-cell variations on the current distribution within a system of parallel connected cells, a $2 \mathrm{P}$ module is investigated, which is contacted differently. In case (a), the module is contacted at $\mathrm{ST}_{\text {mid }}$, with symmetric cell connectors in between cell 1 and cell 2 . In case (b) and (c), the module is contacted asymmetrically at $\mathrm{ST}_{\text {side }}$, with cell 1 being located closer to the ST than cell 2. The modules are subjected to different parametric gradients.

Figure 6 shows the resulting current distribution during a $1 C$ discharge over the respective system's depth of discharge (DOD). The left hand side of the figure shows the schematic ECMs of the systems and relates the positions of the cells to the used line types according to the cell shading. The currents within the homogeneous system are displayed by gray lines. When inhomogeneities are induced, the solid shaded cell has a smaller capacity, a higher impedance or a lower initial temperature than the dashed shaded cell. The main part of the figure shows the current distribution due to a $d C$ (purple lines), $d R$ (green lines) and $d T$ (orange lines) inhomogeneity respectively. The dots mark the maximum observed peak currents.

In all cases except for connected homogeneous cells under a $\mathrm{ST}_{\text {mid }}$ contacting (compare case (a)), the cells show an inhomogeneous current distribution. Each of the systems is discharged with a $1 C$ system current, which should lead to a discharge current of $1 C$ per cell. Due to the cell-to-cell inhomogeneity, the currents of the two cells are not equal but symmetric around the applied $C$-Rate per cell $(=1 C)$. A $1 C$ cell current is only reached for homogeneous cells which are contacted at $\mathrm{ST}_{\text {mid }}$ (compare (a.1)). When inhomogeneous cells are 
Table III. Physicochemical model parameters for the porous electrode and separator domain at $T_{\text {amb }}=25^{\circ} \mathrm{C}$ and $v_{\text {Air }}=1.0 \mathrm{~ms}^{-1}$. Exponent glossary: $\mathrm{e}=$ estimated, $\mathrm{m}=$ measured. The analytical equations are given in the appendix.

$\begin{array}{lll} & \text { Negative Electrode } & \text { Positive Electrode } \\ \text { Parameter } & \left(\mathrm{Li}_{\mathrm{x}} \mathrm{C}_{6}\right) & \mathrm{Separator}^{\left(\mathrm{Li}_{\mathrm{y}} \mathrm{FePO}_{4}\right)}\end{array}$

\section{Geometry}

Electrode length $x_{\text {elec }}$

Electrode height $y_{\text {elec }}$

Electrode area $A_{\text {elec }}$

Electrode thickness $t_{\text {elec }}$

Particle radius $r_{\mathrm{p}}$

Electrode active material volume fraction $\varepsilon_{\mathrm{s}}$

Electrode porosity $\varepsilon_{1}$

Active specific surface area $a_{\mathrm{V}}$

Tortuosity $\tau$

\section{Thermodynamics}

Equilibrium voltage $E_{\text {eq }}$

Entropic coefficient $\frac{d E_{\mathrm{eq}}}{d T}$

Maximum lithium concentration $c_{\mathrm{s}, \max }$

Initial state of charge $\frac{c_{\mathrm{s}, 0}}{c_{\mathrm{s}, \mathrm{max}}}$

\section{Kinetics}

Reaction rate reference $k_{\text {ref }}$

Activation energy for reaction $E_{\mathrm{a}, \mathrm{k}}$

Anodic charge-transfer coefficient $\alpha_{a}$

Cathodic charge-transfer coefficient $\alpha_{c}$

\section{Transport}

Solid diffusivity (reference) $D_{\mathrm{s} \text {, ref }}$

Activation energy for diffusion $E_{\mathrm{a}, \mathrm{D}_{\mathrm{s}}}$

Solid electric conductivity $\sigma_{\mathrm{s}}$

$140 \mathrm{~cm}^{\mathrm{m}}$
$5.6 \mathrm{~cm}^{\mathrm{m}}$
$0.1568 \mathrm{~m}^{2 \mathrm{~m}}$
$61 \mu \mathrm{m}^{\mathrm{m}}$
$3.5 \mu \mathrm{m}^{\mathrm{m}}$
$0.46^{\mathrm{e}}$
$0.30^{\mathrm{e}}$
$\frac{3 \varepsilon_{\mathrm{s}}}{r_{\mathrm{p}}}$
$\left(4.7 \cdot \varepsilon_{1, \text { neg }}^{-0.1}\right)^{77}$

$f(x)(\text { Eq. A1 })^{73}$

$f(x)$ (Eq. A3) $)^{69}$

$31370 \mathrm{~mol} \mathrm{~m}^{-373}$

$0.78^{\mathrm{e}}$

$0.3 \times 10^{-11} \mathrm{~ms}^{-1 \mathrm{e}}$
$3.0 \times 10^{4} \mathrm{~J} \mathrm{~mol}^{-170}$
$0.5^{78}$
$0.5^{78}$

$2.0 \times 10^{-14} \mathrm{~m}^{2} \mathrm{~s}^{-173}$
$2.0 \times 10^{4} \mathrm{~J} \mathrm{~mol}^{-170}$
$100 \mathrm{~S} \mathrm{~m}^{-179}$
$140 \mathrm{~cm}^{\mathrm{m}}$
$5.6 \mathrm{~cm}^{\mathrm{m}}$
$0.1568 \mathrm{~m}^{2 \mathrm{~m}}$
$79 \mu \mathrm{m}^{\mathrm{m}}$
$0.05 \mu \mathrm{m}^{\mathrm{m}}$
$0.48^{\mathrm{e}}$
$0.30^{\mathrm{e}}$
$\frac{3 \varepsilon_{\mathrm{s}}}{r_{\mathrm{p}}}$
$\left(3.1 \cdot \varepsilon_{1, \text { pos }}^{-0.6}\right)^{77}$

$f(y)(\text { Eq. A2 })^{73}$

$f(y)(\text { Eq. A4 })^{74}$

$22806 \mathrm{~mol} \mathrm{~m}^{-373}$

$0.02^{\mathrm{e}}$

Parameter

Electrolyte

Liquid Phase

Electrolyte diffusivity $D_{1}$

Electrolyte ionic conductivity $\mathrm{\kappa}_{1}$

Activity dependency $\frac{\partial \ln f_{ \pm}}{\partial \ln c_{1}}$

Transport number $t_{+}$

$f\left(c_{1}, T\right)$ (Eq. A5) $)^{68}$
$f\left(c_{1}, T\right)$ (Eq. A6)
$f\left(c_{1}, T\right)$ (Eq. A7)
$0.38^{68}$
Parameter

Current collector length $x_{\text {coll }}$

Current collector width $y_{\text {coll }}$

Current collector thickness (single coated) $t_{\text {coll }}$

Current collector material resistivity $\rho_{\text {coll }}$

Current collector specific electrical resistance $R_{\text {coll }}$
Negative current collector $(\mathrm{Cu})$

$140 \mathrm{~cm}$
$5.6 \mathrm{~cm}$
$5.5 \mu \mathrm{m}$
$1.72 \times 10^{-2} \Omega \mathrm{mm}^{2} \mathrm{~m}^{-1}$
$27.8 \mathrm{~m} \Omega \mathrm{m}^{-1}$

Positive current collector $(\mathrm{Al})$

$140 \mathrm{~cm}$
$5.6 \mathrm{~cm}$
$7.5 \mu \mathrm{m}$
$2.65 \times 10^{-2} \Omega \mathrm{mm}^{2} \mathrm{~m}^{-1}$
$31.5 \mathrm{~m} \Omega \mathrm{m}^{-1}$

connected, in all cases except for (a.1), a turning point (TP) of the two currents can be observed during the discharge of the system. The cell which has delivered a higher current before the TP, delivers a smaller current afterwards and vice versa. The current distribution between the two connected cells depends on the ratio between their respective sum of contributions to the string's electric potential versus electric ground. These contributions are on the one hand the influence of the cell's open circuit voltage (OCV), as well as the internal polarization of the cell during operation. On the other hand, also the external polarization due to the cell interconnection resistances contributes to a string's electric potential. At the TP, the sums of these contributions to the electric potential of the two parallel connected strings are equal. Therefore, the currents through the two strings are equal at the TP. Towards the end of discharge (EOD) of the system, the two currents first diverge and then subsequently converge again. The divergence occurs when the limiting cell reaches its EOD. Then its internal polarization increases, the cell cannot deliver the required current any more and the remaining cell must therefore deliver an even higher current. Finally, also this second cell cannot deliver this high current any more, the two currents converge again and the EOD of the system is reached.

The inhomogeneity observed in case (a) is enhanced when the cells are contacted asymmetrically (compare case (b) and (c)). In these cases, also the influence of the asymmetric current collector design is present. The colored curves within cases (b) and (c) can therefore be considered the sum of the gray lines for that specific case and the colored curves of case (a) to account for the respective additional cell-to-cell variation.

$2 P$ module contacted at $S T_{\text {mid }}$ - - Under a $d C$ cell-to-cell variation, one cell (cell 1 in (a.1) and (b.1)) is attributed a smaller amount of active material within the negative electrode $\varepsilon_{\mathrm{s}, \text { neg }}$. This decreases the active specific surface area $a_{\mathrm{v}}$, which influences the local current source $i_{\mathrm{v}}$. A higher absolute internal polarization $\left|\eta_{1}\right|$ results in a 
smaller absolute discharge current $\left|i_{1}\right|$. In order to being able to provide the required system current $i_{\text {app }}$, cell 2 is discharged with a higher absolute discharge current $\left|i_{2}\right|>\left|i_{1}\right|$. Within a module which is contacted at $\mathrm{ST}_{\text {mid }}$ (compare Figure 6a.1), this results in cell 1 being discharged less than cell 2 throughout the whole discharge period.

A $d R$ variation between the two cells with cell 1 being attributed a higher $R_{\text {foil }}$ than cell 2 (compare Figure 6a.2) results in a higher internal polarization $\left|\eta_{1}\right|$ and therefore an initially smaller discharge current $\left|i_{1}\right|$ through cell 1 . At the TP, the sums of the contributing parts to the electric potential of the strings are equal, after which cell 1 is discharged more than cell 2 until the EOD.

Under a $d T$ variation (compare Figure 6a.3), a smaller cell temperature $T_{\text {ref1 }}$ results in a worse lithium diffusivity within the electrode active materials and both, a worse lithium diffusivity and a smaller ionic conductivity within the electrolyte, ${ }^{19}$ which therefore leads to a higher polarization $\left|\eta_{1}\right|$ and therefore to a smaller discharge current $\left|i_{1}\right|$. After the TP, the discharge current through cell 1 exceeds the one through cell 2.

$2 P$ module contacted at $S T_{\text {side }}$ - - When the system is contacted at $\mathrm{ST}_{\text {side }}$, even when homogeneous cells are connected, different currents through the parallel connected strings are observed (compare gray lines in Figure 6 cases (b) and (c)). This is due to the fact that although the cell connector resistances are constant in the simulation, the cells experience different voltage drops relative to the asymmetric ST. $\left(R_{\mathrm{p} 1}, R_{\mathrm{n} 1}\right)$ are exposed to both cell currents $\left(i_{1}+i_{2}\right)$ whereas $\left(R_{\mathrm{p} 2}, R_{\mathrm{n} 2}\right)$ are only passed through by $i_{2}$. Cell 2 is subjected to a higher external polarization versus electric ground than cell 1 . These ohmic polarizations evoke a current distribution within the module which is independent of the induced cell-to-cell variations following the same principle as the current density distribution within single cells. ${ }^{54-58}$ The different string currents lead to a difference within the internal polarizations of the cells, cells' SOCs and OCVs. At the respective TP, this difference equals the difference within the external voltage drops which leads to the string currents being equal at this point. Note, that the gray lines for the homogeneous system are the same for case (b)

\begin{abstract}
Table IV. Geometric, electric and thermal model parameters for the cylindrical cell (multiple materials), cell connector (Hilumin - nickel plated steel) and welding spot joints (between cell pole and cell connector), when the distance between two adjacent cells is $d x_{\text {cell }}=5 \mathrm{~mm}$. The values are chosen for $T_{\mathrm{amb}}=25^{\circ} \mathrm{C}$ and $v_{\text {Air }}=1.0 \mathrm{~ms}^{-1}$. Exponent glossary: $\mathrm{f}=$ fitted, $\mathrm{e}=$ estimated, $\mathrm{m}=$ measured, $\mathrm{c}=$ calculated.
\end{abstract}

Parameter Value

Cell

Radius $r_{\text {cell }}$

Height $h_{\text {cell }}$

Specific heat capacity $c_{\mathrm{p}, \text { cell }}$

Convective heat transfer coefficient $h_{\text {conv }}$

Value

\section{Cell connector}

Length $l_{\text {conn }}$

Width $w_{\text {conn }}$

Thickness $t_{\text {conn }}$

Electric conductivity $\sigma_{\mathrm{conn}}$

Electric resistance $R_{\text {conn }}=R_{\mathrm{p}}=R_{\mathrm{n}}$

Density $\rho_{\text {conn }}$

Specific heat capacity $c_{\mathrm{p}, \mathrm{conn}}$

Thermal conductivity $k_{\text {conn }}$

Electric resistance spot-welded joint $R_{\mathrm{ws}}$

Thermal resistance spot-welded joint $R_{\mathrm{th} \text {,ws }}$
$26.2 \pm 0.2 \mathrm{~mm}$
$65.4 \pm 0.2 \mathrm{~mm}$
$1400 \mathrm{~J} \mathrm{~kg}^{-1} \mathrm{~K}^{-1 \mathrm{f}}$
$22.5 \mathrm{~W} \mathrm{~m}^{-2} \mathrm{~K}^{-1 \mathrm{c}}$

$4.5 \mathrm{~cm}^{\mathrm{m}}$

$1.0 \mathrm{~cm}^{\mathrm{m}}$

$0.5 \mathrm{~mm}^{\mathrm{m}}$

$9.93 \times 10^{6} \mathrm{~S} \mathrm{~m}^{-167}$

$9 \times 10^{-4} \Omega^{\mathrm{c}}$

$7.87 \mathrm{~g} \mathrm{~cm}^{-367}$

$452 \mathrm{~J} \mathrm{~kg}^{-1} \mathrm{~K}^{-1 \mathrm{e}}$

$52 \mathrm{~W} \mathrm{~m}^{-1} \mathrm{~K}^{-167}$

$0.2 \mathrm{~m} \Omega^{81}$

$1 \times 10^{-5} \mathrm{~m}^{2} \mathrm{KW}^{-182}$

and case (c). Depending on whether the 'bad' cell is situated closer to the ST (compare case (b)) or the 'good' cell is (compare case (c)), the inhomogeneity within the system increases or decreases according to the interaction between the effects of the cell-to-cell variation and the asymmetric ST.

A $d C$ variation leads to a more homogeneous current distribution if the cell with the higher capacity is assembled closer to the ST (compare purple lines in Figure 6c.1). In this case, also smaller

(a)

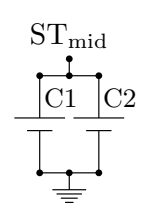

(b)

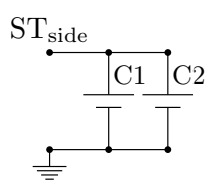

(c)

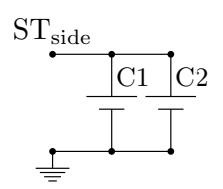

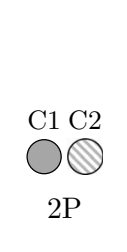
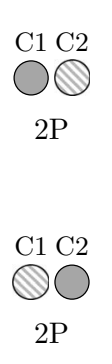
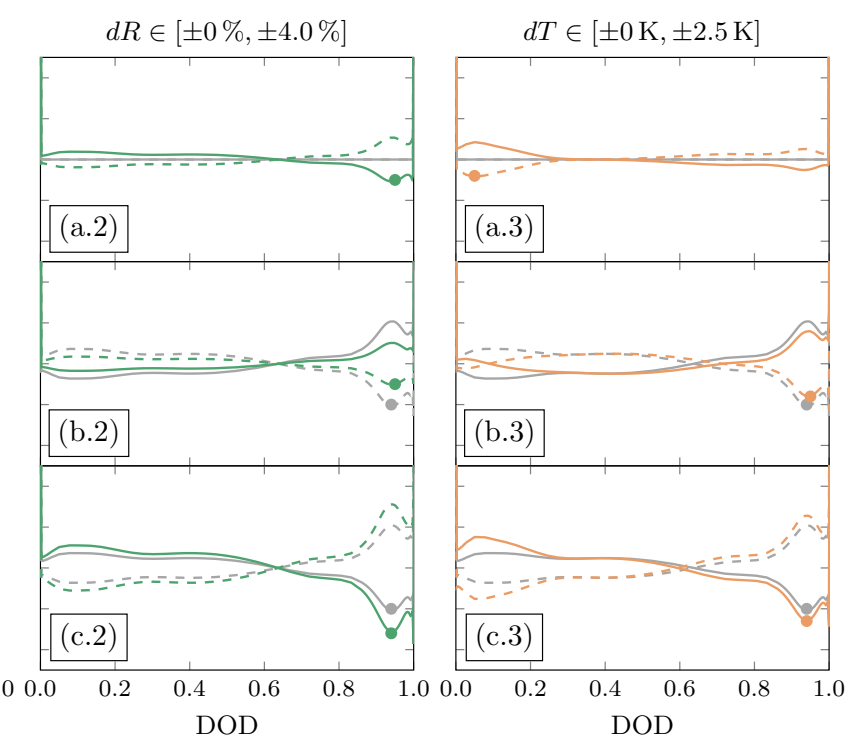

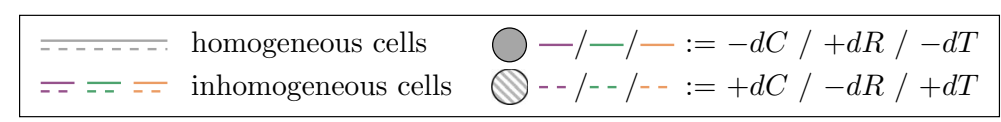

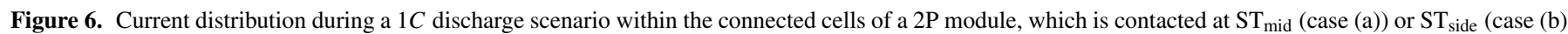

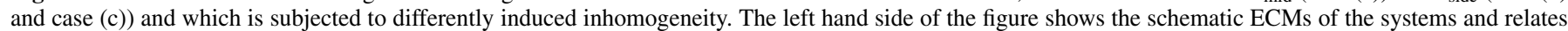

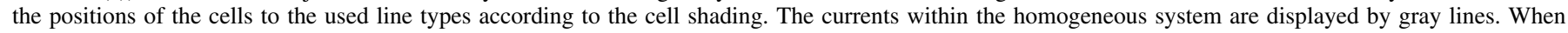

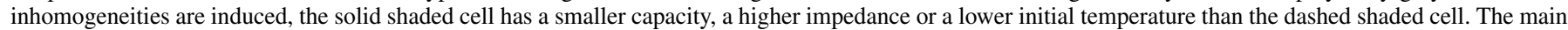

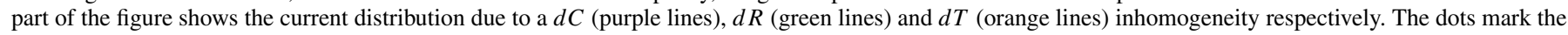
maximum observed peak currents. 
peak currents are observed. The increased $\varepsilon_{\mathrm{s}, \mathrm{neg}, 1}$ results in a smaller absolute polarization $\left|\eta_{1}\right|$, which initially further increases the already larger absolute current through cell 1 due to the asymmetric connection $\left|i_{1}\right|>\left|i_{2}\right|$. This higher current increases the internal polarization $\left|\eta_{1}\right|$, which works against the influence of the higher external resistances which are seen by cell 2 . Therefore, the current deviation toward the EOD and the peak currents are reduced. Over the whole discharge period, the current distribution is more homogeneous.

In order to reach a more homogeneous current distribution under an induced $d R$ variation, the cell with the higher impedance should be assembled closer to the ST (compare green lines in Figure 6b.2). The difference within the internal polarizations works against the difference in the external potential drops. Therefore, in the beginning of the discharge, cell 2 is discharged less than cell 1 and the current deviation is smaller than for the homogeneous system. Towards the EOD of the system, cell 1 shows a smaller absolute internal polarization, which results in a larger absolute discharge current $\left|i_{1}\right|$ compared to the homogeneous system. Therefore, the current deviation between the cells after the TP is still smaller than for the homogeneous system.

When the module is subjected to a thermal gradient $d T$, the current distribution is more homogeneous when the cell with the lower ambient temperature is assembled closer to the ST (compare orange lines in Figure 6b.3). Due to the smaller cell temperature $T_{\text {refl } 1}$, the internal polarization $\left|\eta_{1}\right|$ is increased and works against the influence of the asymmetric ST contact. This not only results in a smaller current deviation between the cells but also in smaller peak currents within the system.

The observed maximum peak currents per cell within the different systems differ dependent on the ST position, the induced variations and the position of the 'good' and 'bad' cell relative to the ST (compare dot marks in Figure 6). For case (a) the absolute peak currents lie by $6 \%(d C), 5 \%(d R)$, and $4 \%(d T)$ above the intended $C$-Rate of $1 C$. For a connection at $\mathrm{ST}_{\text {side }}$ (cases (b) and (c)), even for homogeneous connected cells, the peak currents exceed $1 C$ by $10 \%$. With the 'bad' cell being situated close to the ST (compare Figure 6 case (b)) the observed maximum peak currents per system change to $16 \%(d C)$, $5 \%(d R)$, and $8 \%(d T)$ above $1 C$. With the 'good' cell being situated close to the ST (compare Figure 6 case $(c)$ ) the observed maximum peak currents per system change to $4 \%(d C), 16 \%(d R)$, and $13 \%$ $(d T)$ above $1 C$. Therefore, the peak currents within an asymmetrically contacted module can be lowered, if the cell with the higher capacity, higher impedance or lower ambient temperature is situated close to the ST.

The Ah-throughput of the parallel connected cells differ according to the respective current distribution. Figure 7 shows the exemplary results for a $2 \mathrm{P}$ module under an $\mathrm{ST}_{\text {side-connection when being dis- }}$ charged by $1 C$. The plots refer to the investigation shown in Figures $6 \mathrm{~b}$ and $6 \mathrm{c}$ under the same induced $d C, d R$ and $d T$ variation.

Figures $7 \mathrm{a}$ to $7 \mathrm{c}$ show that the Ah which are put through the individual cells diverge during the discharge regime but converge again toward the EOD except for a $d C$ variation under a case (b) assembly. Figures $7 \mathrm{~d}$ to $7 \mathrm{f}$ show the absolute difference in Ah-throughput between the two cells $\left|\Delta A h_{\text {cell }}\right|=\left|A h_{\text {cell1 }}-A h_{\text {cell2 }}\right|$. For a $d C$ variation under a case (b) assembly (compare dotted line in Figure $7 d$ ), the Ah-difference increases toward the EOD. This is due to the fact that the absolute Ah-difference is depicted, wherefore a negative difference is displayed as a positive value. Thus, the Ah-difference at the EOD between the two cells is negative for a case (b) assembly and positive for a case (c) assembly under a $d C$ variation. For a $d R$ and $d T$ variation, the Ah-difference vanishes toward the EOD. The maximum deviation in Ah between the connected cells emerges at the respective TP of the two cell currents (compare Figure 6 case (b) and case (c)). These maxima correspond to about $4 \%$ of the nominal capacity of the cell $C_{\text {nom }}=3 \mathrm{Ah}$, which is high compared to reported values by Erhard et al. ${ }^{57}$ and Kosch et al. ${ }^{58}$ This is due to the fact that the cell investigated here is an lithium iron phosphate (LFP) cell with a very flat OCV which does not allow for a OCV gradient driven balancing between the cells. The other investigated cell was a lithium nickel manganese cobalt oxide (NMC) cell which has a steeper OCV,
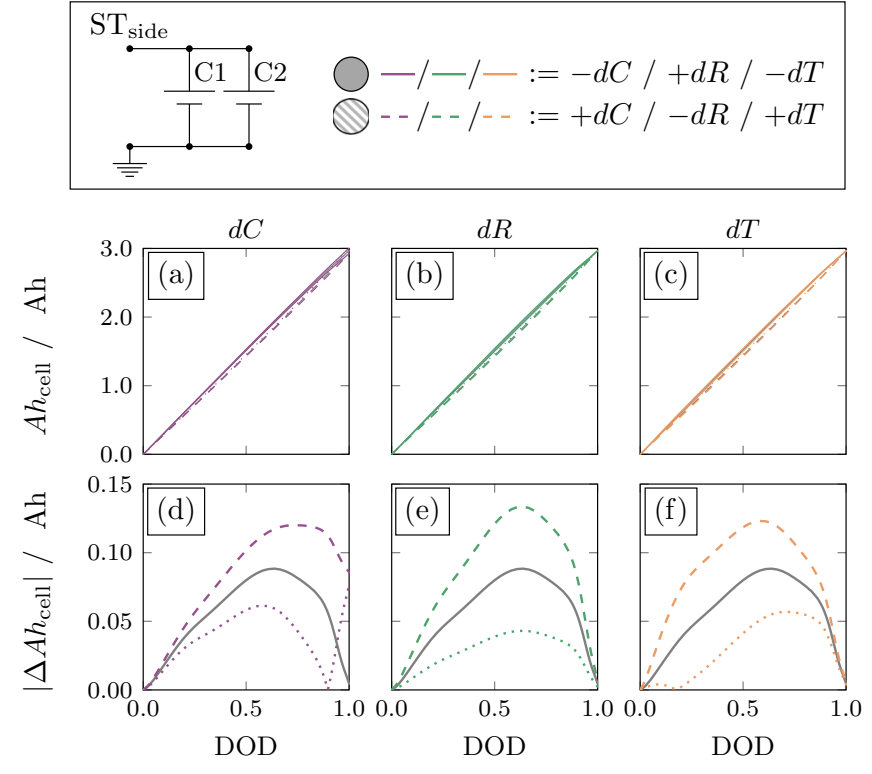

Figure 7. Cumulated Ah-throughput $A h_{\text {cell }}$ through the parallel connected cells within a $2 \mathrm{P}$ module contacted at $\mathrm{ST}_{\text {side }}$ during a $1 C$ discharge. Graphs (a), (b) and (c) show the results for a $d C, d R$ and $d T$ variation respectively. In graphs (d), (e) and (f) the absolute difference in Ah-throughput between the two cells $\left|\Delta A h_{\text {cell }}\right|=\left|A h_{\text {cell1 }}-A h_{\text {cell2 }}\right|$ is given. Homogeneous cells are depicted by gray lines, inhomogeneous cells are depicted by colored dotted (for case (b) in Figure 6) or dashed (for case (c) in Figure 6) lines.

which therefore allows for a balancing as soon as a SOC difference is present. ${ }^{57,58}$ The maximum deviation in Ah between the connected cells is smaller, if the cell with a lower capacity or higher impedance is assembled close to the ST. This is a different cell matching recommendation than when aiming to reduce peak currents within the system. Different optimization scenarios ask for different cell matching recommendations. Exposing the ST to the smaller ambient temperature on the other hand will reduce both, the Ah difference as well as the peak currents within the system.

Regarding the presented results, in case the discharge of the system was stopped right before the TP of the cell currents, the deviation between the individual $A h_{\text {cell }}$ is maximum. If this partial discharge was directly followed by a CC-charge $(\mathrm{CH})$, the deviation between the individual $A h_{\text {cell }}$ will adapt further. Therefore, cycling a system of inhomogeneous parallel connected cells will not only lead to the individual cells experiencing different current rates but might also result in differently aged cells within the module over operation time.

Comparing the observed current distribution under a symmetrically and an asymmetrically contacted module, it becomes clear that a symmetric design of cell connectors results in a symmetric current distribution between two homogeneous parallel connected cells, whereas an asymmetric design results in asymmetric currents due to the resistances of the cell connectors. Under the simulated $d C, d R$, and $d T$ cell-to-cell variations and assembled cell connectors, an asymmetric design has a much larger impact on the current deviation than cell-to-cell variations do. Regarding the presented investigation, cell matching can minimize the peak currents within an asymmetrically contacted module, if the cell with a higher cell internal polarization is assembled close to the ST. This means, that the cell with a higher capacity or higher impedance should be assembled close to the ST. In case thermal gradients are to be expected across the module, the ST should be exposed to the lower ambient temperature. In order to minimize the Ah difference between the cells, the cell with a lower capacity or higher impedance shall be assembled close to the ST. Exposing the ST to the smaller ambient temperature will further decrease the Ah difference. 
(a)

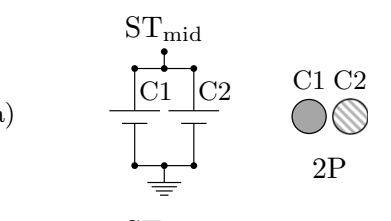

(b)

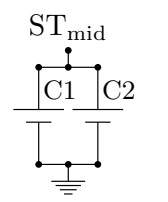

(c)

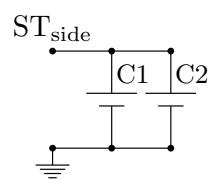

(d)

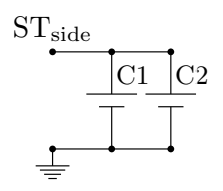

aco
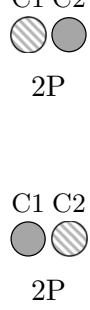

$\mathrm{C} 1 \mathrm{C} 2$

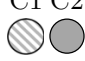

$2 \mathrm{P}$

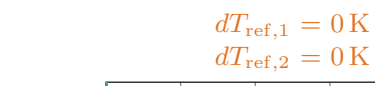

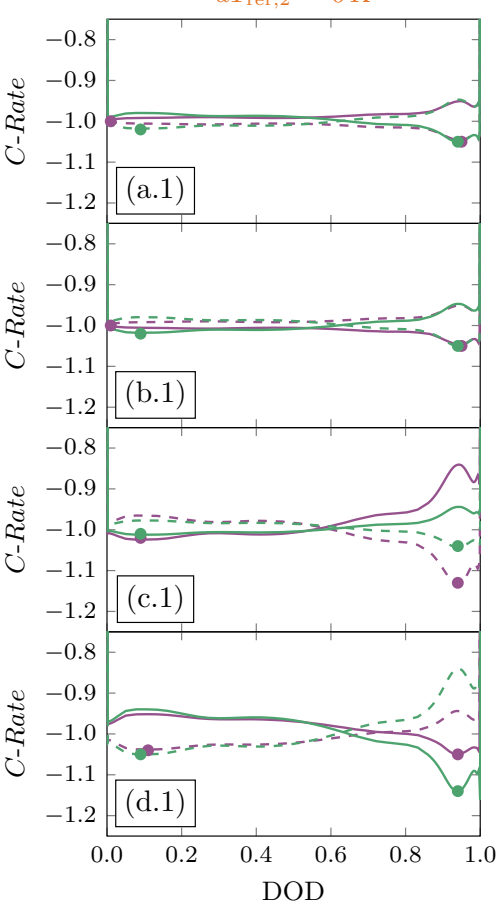
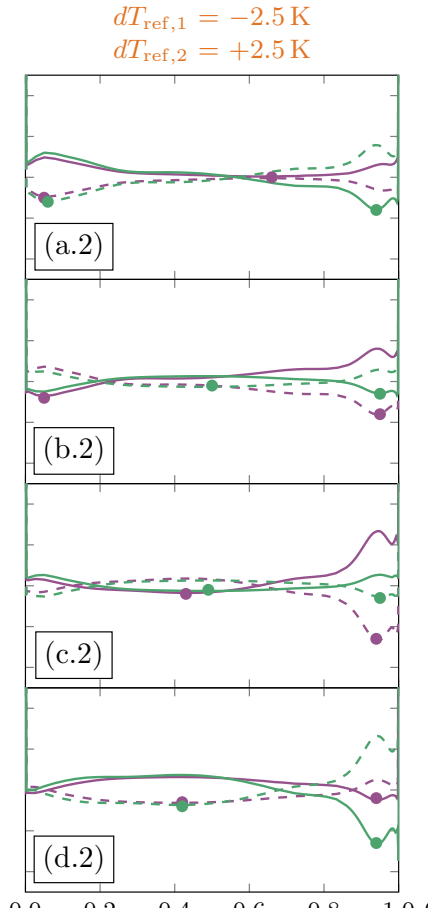

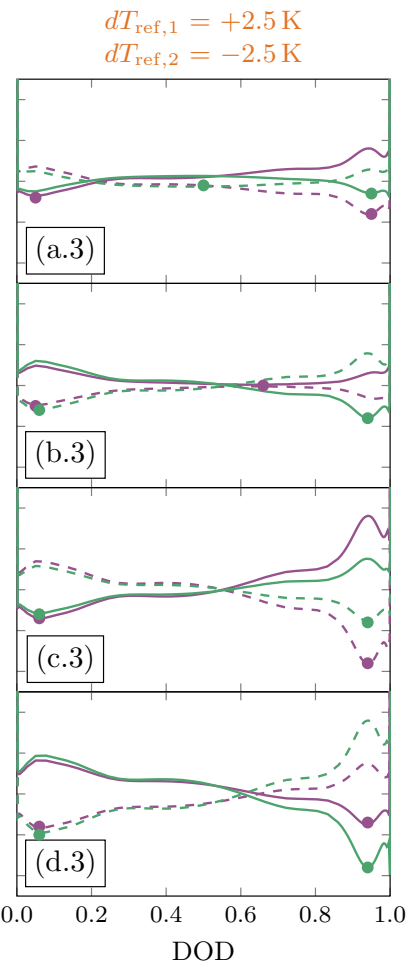

DOD

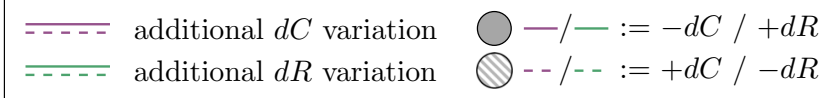

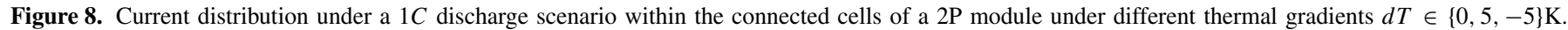

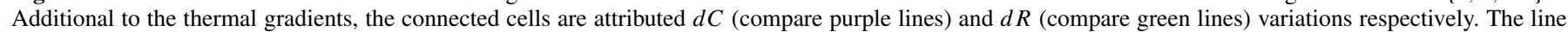

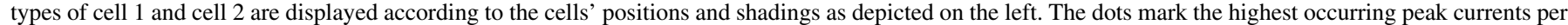
cell per variation.

Cell matching strategies for peak current reduction.-The following studies will focus on the discussion of peak current reduction during operation. As depicted in Figure 6, peak currents which exceed the intended $C$-Rate per cell can occur within a system of parallel connected cells due to both, cell-to-cell variations and module design related reasons such as thermal gradients or an asymmetric cell connection design.

From a battery module manufacturer's view, inhomogeneity can thus be reduced if either the assembled cells are matched, or if the thermal management or cell connectors are designed according to the optimization scenario.

Assembling cells under an expected thermal gradient.-In case a thermal gradient across the battery module is to be expected due to an external heat source at one end of the module or due to thermal management design, it will affect the degree of impact which cellto-cell variations have on the inhomogeneous current distribution. Figure 8 shows the resulting current distribution for a $2 \mathrm{P}$ module which is exposed to a thermal gradient of $d T \in\{0,5,-5\} \mathrm{K}$. Additional to each of these thermal gradients, the connected cells are attributed $d C$ (compare purple lines) and $d R$ (compare green lines) variations respectively. The line types refer to the cells' positions and shadings as depicted on the left of the respective case. The highest occurring peak currents per cell are additionally highlighted in the graphs by colored dots.

The values of these highest occurring peak currents per system are given in Table $\mathrm{V}$ for each of the cases depicted in Figure 8 and for both, the additional $d C$ and $d R$ variation.

If no thermal gradient is present across a battery module which is contacted at $\mathrm{ST}_{\text {mid }}$ (compare Figures 8a.1 and 8b.1), both, the induced $d C$ and $d R$ variation result in a maximum peak current of $5 \%$ above the intended applied $C$-Rate per cell. As the cell connectors are symmetric, the inverted assembling of the cells has no effect. This is straight forward but is still mentioned for the sake of completeness. For a module contacted at $\mathrm{ST}_{\text {side }}$ however (compare Figures $8 \mathrm{c} .1$ and 8d.1), the positioning of the cells has an effect on the resulting peak currents, as already discussed in Inhomogeneous current distribution due to cell-to-cell variations section.

If cell 1 is exposed to the lower ambient temperature $\left(d T_{\mathrm{ref}, 1}=\right.$ $-2.5 \mathrm{~K})$ and cell 2 is exposed to the higher ambient temperature $\left(d T_{\text {ref }, 2}=+2.5 \mathrm{~K}\right)$ (compare Figures $8 \mathrm{a} .2$ and $\left.8 \mathrm{~b} .2\right)$ under $\mathrm{ST}_{\text {mid }}$, the peak currents are reduced if the colder cell has the smaller capacity and smaller impedance. Under $\mathrm{ST}_{\text {side }}$ (compare Figures $8 \mathrm{c} .2$ and 8d.2),

\footnotetext{
Table V. Resulting maximum peak currents above the intended applied $C$-Rate per cell in \% within a $2 \mathrm{P}$ module which is exposed to different thermal gradients and under additional attributed $d C$ and $d R$ variations. The rows (a), (b), (c) and (d) refer to the respective cases in Figure 8.
}

\begin{tabular}{ccccc} 
Case & $d X$ & $\begin{array}{c}d T_{\text {ref }, 1}=0 \mathrm{~K} \\
d T_{\text {ref }, 2}=0 \mathrm{~K}\end{array}$ & $\begin{array}{c}d T_{\text {ref, } 1}=-2.5 \mathrm{~K} \\
d T_{\text {ref, } 2}=+2.5 \mathrm{~K}\end{array}$ & $\begin{array}{c}d T_{\text {ref, } 1}=+2.5 \mathrm{~K} \\
d T_{\text {ref, }, 2}=-2.5 \mathrm{~K}\end{array}$ \\
\hline a) & $d C$ & $5 \%$ & $5 \%$ & $8 \%$ \\
& $d R$ & $5 \%$ & $8 \%$ & $3 \%$ \\
(b) & $d C$ & $5 \%$ & $8 \%$ & $5 \%$ \\
& $d R$ & $5 \%$ & $3 \%$ & $8 \%$ \\
(c) & $d C$ & $13 \%$ & $13 \%$ & $18 \%$ \\
& $d R$ & $4 \%$ & $3 \%$ & $8 \%$ \\
(d) & $d C$ & $5 \%$ & $3 \%$ & $8 \%$ \\
& $d R$ & $14 \%$ & $13 \%$ & $18 \%$
\end{tabular}


Table VI. Electrical resistance data for cell connectors of different material and thickness. The length and width of all connectors is $l_{\text {conn }}=4.5 \mathrm{~cm}$ and $w_{\text {conn }}=1 \mathrm{~cm}$ respectively as already given in Table IV. The previously presented results have been modeled based on the data for the Hilumin strip in $0.5 \mathrm{~mm}$ thickness. The last column of the table gives the ratio between the respective connector resistance and the nominal cell internal resistance $\left(R_{\text {cell }}=18 \mathrm{~m} \Omega\right)$ in \%.

\begin{tabular}{lcccc} 
Connector & $\begin{array}{c}\sigma_{\text {conn }} \\
\left(\mathrm{Sm}^{-1}\right)\end{array}$ & $\begin{array}{c}t_{\text {conn }} \\
(\mathrm{mm})\end{array}$ & $\begin{array}{c}R_{\text {conn }} \\
(\mathrm{m} \Omega)\end{array}$ & $\begin{array}{c}\frac{R_{\text {conn }}}{R_{\text {cell }}} \\
(\%)\end{array}$ \\
\hline Copper bar & $5.96 \times 10^{7}$ & 2.0 & 0.04 & 0.2 \\
Copper strip & $5.96 \times 10^{7}$ & 0.5 & 0.15 & 0.8 \\
Aluminum strip & $3.77 \times 10^{7}$ & 0.5 & 0.24 & 1.3 \\
Hilumin strip & $9.93 \times 10^{6}$ & 0.5 & 0.90 & 5.0 \\
Hilumin strip thin & $9.93 \times 10^{6}$ & 0.2 & 2.30 & 12.8
\end{tabular}

the peak currents are reduced if the colder cell (in this case next to the ST) has the higher capacity and higher impedance.

If cell 1 is exposed to the higher ambient temperature ( $d T_{\text {ref,1 }}$ $=+2.5 \mathrm{~K})$ and cell 2 is exposed to the lower ambient temperature $\left(d T_{\text {ref, } 2}=-2.5 \mathrm{~K}\right)$ (compare Figures $8 \mathrm{a} .3$ and $\left.8 \mathrm{~b} .3\right)$ under $\mathrm{ST}_{\text {mid }}$, the peak currents are reduced if the colder cell has the smaller capacity and smaller impedance. Under $\mathrm{ST}_{\text {side }}$ (compare Figures $8 \mathrm{c} .3$ and 8d.3), the peak currents are reduced if the colder cell (in this case further away from the ST) has the smaller capacity and smaller impedance.

Therefore, if the maximum occurring peak currents during a full $\mathrm{CC}-\mathrm{DCH}$ shall be reduced under $\mathrm{ST}_{\text {mid }}$, the cell with the smaller capacity or impedance should be assembled toward the lower ambient temperature. Under $\mathrm{ST}_{\text {side }}$, it has to be differentiated whether the ST is exposed to the lower or higher ambient temperature. If the ST is exposed to the lower ambient temperature, the cell with the higher capacity or higher impedance should be assembled close to the ST. If the ST is exposed to the higher ambient temperature, the cell with the smaller capacity or smaller impedance should be assembled close to the ST.

Note, that these results depend on the chosen ranges of investigated $d C, d R$ and $d T$ variations. For other ranges, the results might adapt. In our previous investigation ${ }^{5}$ we have found, that the capacity and impedance of fresh cells show neither a positive nor a negative correlation. Nevertheless this also means that, within a batch of cells, there are cells which show both, a higher capacity and a higher impedance relative to the mean values of the batch. Assembling such a cell well or bad will have an even larger impact on the inhomogeneous current distribution within a module than under the above presented variations.

Comparing the results of an $\mathrm{ST}_{\text {mid }}$ contact with those of an $\mathrm{ST}_{\text {side }}$ contact, it can be observed that the peak currents within the $\mathrm{ST}_{\text {mid }}$ topologies are smaller. This is due to the lacking additional influence of the cell connector resistances on the current distribution, which are present within an asymmetrically contacted module. The assembled cell connector resistances $R_{\text {conn }}$ seem to have a similar if not larger impact on the current distribution within asymmetrically contacted modules than the induced variations or exposed thermal gradients. This influence will be further investigated in the following.

Influence of cell connector resistances on resulting peak currents.-Cells can be connected by cell connectors of different material and thickness. These will lead to different cell connector resistances $R_{\text {conn }}$. In the following, the peak currents within an $\mathrm{ST}_{\text {side }}{ }^{-}$ connection are investigated depending on the ratio of $R_{\text {conn }}$ to $R_{\text {cell }}$. $R_{\text {cell }}=18 \mathrm{~m} \Omega$ is the nominal resistance of the investigated cell. The cell connectors which are to be compared, are a copper bar, a copper strip, an aluminum strip, a Hilumin strip (which has been investigated so far) and a thinner Hilumin strip. They represent a step by step increased electric resistance. The data of the respective connectors are given in Table VI.

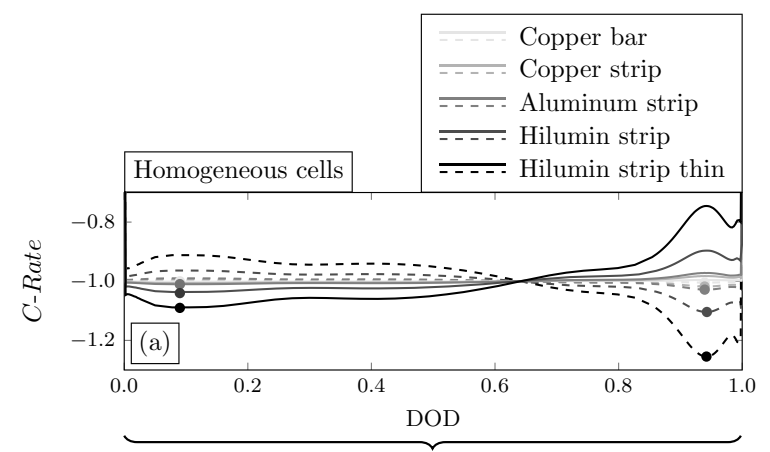

Absolute peak currents relative to applied C-Rate

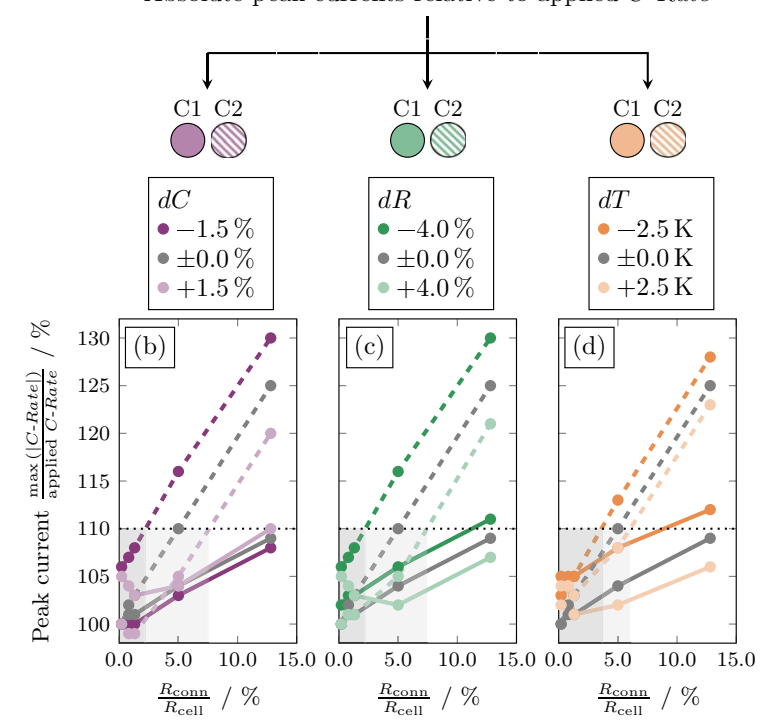

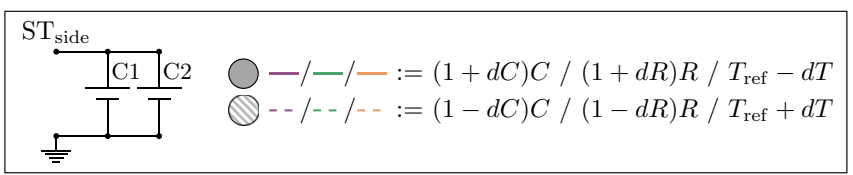

Figure 9. Influence of different cell connector resistances on the observed peak currents within a $2 \mathrm{P}$ module under a $\mathrm{ST}_{\text {side }}$-connection and under a $1 C$ CC-discharge. Graph (a) displays the current distribution for homogeneous connected cells. The lower graphs (b), (c) and (d) depict the observed peak currents per cell relative to the intended applied $C$-Rate per cell in dependence of the different cell connector resistances. They refer to a $d C$ (b), $d R$ (c) and $d T$ (d) variation respectively. The gray lines represent homogeneous cells. The current through cell 1 is depicted by solid lines, the one through cell 2 by dashed lines according to the cells' positions and shadings. The black dotted lines mark a threshold peak current of $10 \%$ above the intended applied $C$-Rate per cell. This threshold value is not exceeded if the cell connectors are chosen from the gray shaded areas. The legend of the depicted scenario is shown in the lower box.

Figure 9a presents the current distribution within a 2P module contacted at $\mathrm{ST}_{\text {side }}$ with homogeneous cells but different cell connectors under a $1 C$ discharge regime. The different cell connectors are depicted by different shades of gray. The connector with the highest cell connector resistance (thin Hilumin strip) is illustrated by the darkest shade of gray. The connector with the lowest cell connector resistance (copper bar) is illustrated by the lightest shade of gray.

The observed peak currents are highlighted within graph (a). The highest peak currents are observed for thin Hilumin strips, which show the highest electric resistance, whereas the smallest peak currents are observed for copper bars. The obtained peak currents are related to the applied $C$-Rate per cell and depicted in Figures 9b, 9c and 9d in gray. Graphs (b), (c) and (d) moreover show the resulting peak currents under a $d C$ variation (purple curves), $d R$ (green curves) and $d T$ (orange curves) variation respectively. The line types refer to 
the cells' positions and shadings. The dark colored curves depict the simulations with a negative $d C, d R$ or $d T$. The light colored curves depict the simulations with a positive $d C, d R$ or $d T$. The legend of Figure 9 states, how the $d C, d R$ and $d T$ variation affects the respective capacity, impedance and temperature of the two connected cells.

Analyzing the gray colored curves for homogeneous cells, it becomes clear that the observed peak currents increase for both cells with increasing cell connector resistance $R_{\text {conn }}$. Moreover, the cell which is situated further away from the ST experiences a higher peak current (note, that the dashed line is above the solid line for all $R_{\text {conn }}$ ). Using a $2 \mathrm{~mm}$ thick copper bar as cell connector minimizes the absolute current peaks to less than $1 \%$ above the intended applied $C$-Rate. For a $0.2 \mathrm{~mm}$ thin Hilumin strips however, the peak current will exceed the intended $C$-Rate by as much as $25 \%$.

In contrast to homogeneous connected cells, the peak currents are not necessarily the smallest for low resistant cell connectors, as soon as cells under any type of cell-to-cell variation $(d C, d R$ and $d T)$ are connected. The light colored curves show the smallest overall peak currents within the system for aluminum strips. For each of the $d C, d R$ and $d T$ variations an excess of $3 \%$ over $1 C$. With even smaller $R_{\text {conn }}$ (i.e. copper strips or bars) the maximum observed peak currents increase again. This is due to the fact that the cell connector resistances work against the difference in cell internal overpotentials due to variations if the cells are matched accordingly. Smaller $R_{\text {conn }}$ are too small to level the existing variations and the peak currents are therefore larger. Using thin Hilumin strips as cell connectors under $d C, d R$ and $d T$ variations results in peak currents of $20 \%, 21 \%$ and $23 \%$ above $1 C$ for well matched cells and of $30 \%, 30 \%$ and $28 \%$ above $1 C$ for badly matched cells. Note, that these values depend on the simulated variation ranges. With the ranges used in this study, a $d C$ variation of $-1.5 \%$ results in the same maximum peak currents through cell 2 as a $d R$ variation of $-4.0 \%$ (compare dark colored dashed lines in (b) and (c)).

For all types of cell-to-cell variation $(d C, d R$ and $d T)$ and independent of the chosen cell connectors, both light colored curves lie beneath the highest dark colored curve. The highest peak currents are observed for the respective highest dark colored curve - if the cell with the low capacity, low impedance or high ambient temperature is assembled close to the ST. In other words, peak currents can be reduced, if the cell with the higher capacity or higher impedance is assembled close to the ST - and this is independent of the chosen cell connectors. Whether the cell close to the ST experiences the highest peak current or whether the other cell does, depends on the assembled cell connectors. In case thermal gradients are to be expected across the module, the ST should be exposed to the lower ambient temperature.

From a manufacturer's point of view the question arises, how the appropriate cell connector for a battery module shall be chosen in order to ensure that the peak currents will not exceed a certain threshold value

1. if the individual cells' capacity and impedance have not been determined prior to the module assembly and the cells might therefore be arbitrarily connected in a bad matching scenario.

2. if the individual cells' capacity and impedance have been determined prior to the module assembly and therefore a matching approach can be followed.

Figure 9 can be used to answer these questions by choosing the appropriate cell connectors dependent on the occurring cell-to-cell variations and tolerable threshold peak current. Arbitrarily, the tolerable peak current through any of the connected cells is assumed to be $10 \%$ above the intended applied $C$-Rate per cell (compare black dotted lines in Figure 9). For a $1 C$ discharge as depicted in Figure 9, each cell would be allowed to experience a peak current of $1.1 C$.

Regarding question (1), in order to not exceed the chosen threshold value and to compensate a possible bad matching in capacity, impedance or thermal gradient across the module, the ratio of cell connector resistance to cell impedance $\frac{R_{\text {conn }}}{R_{\text {cell }}}$ should lie within the dark gray shaded areas in Figures $9 \mathrm{~b}$ to $9 \mathrm{~d}$. In this case, the cell connector

$\begin{aligned} & \text { Table VII. Maximum suitable cell connector resistance values } \\
& \text { relative to the cell impedance } \frac{\boldsymbol{R}_{\text {conn }}}{\boldsymbol{R}_{\text {cell }}} \text { and corresponding cell } \\
& \text { connector material in order to not exceed a threshold peak current } \\
& \text { of } 10 \% \text { above the intended applied } \boldsymbol{C} \text { - } \text { Rate per cell. }\end{aligned}$
\begin{tabular}{lcccc} 
Matching & $d C$ & $d R$ & $d T$ & Cell connector \\
\hline bad & $2.2 \%$ & $2.2 \%$ & $3.7 \%$ & Aluminum strip \\
homogeneous & $5.0 \%$ & $5.0 \%$ & $5.0 \%$ & Hilumin strip \\
good & $7.5 \%$ & $7.4 \%$ & $6.0 \%$ & Hilumin strip
\end{tabular}

could be made of a copper bar, a copper strip or an aluminum strip. The respective maximum suitable percentage values of $\frac{R_{\text {conn }}}{R_{\text {cell }}}$ and the corresponding cell connector material are given in Table VII.

Regarding question (2), if the cell-to-cell variations are known prior to the module assembly, and if the cells are matched accordingly, then the allowed range, from which the cell connector can be chosen, increases (compare additional light gray shaded areas in Figures 9b to $9 \mathrm{~d})$. In this case, the cell connector could additionally be made of a Hilumin strip.

Implications for assembling battery modules.-From the results, five implications for assembling battery modules can be extracted regarding the connection of cells which show cell-to-cell variations.

1. A symmetric design of cell connectors results in a symmetric current distribution between two homogeneous parallel connected cells, whereas an asymmetric design results in asymmetric currents.

2. An asymmetric design of cell connectors can have a much larger impact on an inhomogeneous current distribution within a battery module than cell-to-cell parametric variations do. The extent of this impact depends on the resistances of the assembled cell connectors and on the assembled cell-to-cell variations.

3. Even if the connected cells were homogeneous in capacity and impedance and if the battery module was not subjected to an external thermal gradient, current peaks of $25 \%$ above the intended applied $C$-Rate per cell have been observed during a $1 C \mathrm{CC}$ discharge for thin Hilumin strips. When using copper bars as cell connectors however, the excess peak currents can be reduced to $1 \%$.

4. If the arrangement of the cells within the module is chosen disadvantageously under a $d C, d R$ or $d T$ variation, these current peaks can increase to about $6 \%$ above $1 C$ under the usage of copper bars and to even about $30 \%$ under the usage of thin Hilumin strips respectively.

5. Matching the cells during module assembly can minimize the peak currents inside an asymmetrically contacted module. Independent of the chosen cell connectors, the peak currents are reduced if the cell with a higher cell internal polarization is assembled close to the ST. This means, that the cell with a higher capacity or higher impedance should be assembled close to the ST. In case thermal gradients are to be expected across the module, the ST should be exposed to the lower ambient temperature.

\section{Conclusions}

We have presented a coupled multiphysics multidimensional model for a $x \mathrm{~S} y \mathrm{P}$ battery module which is able to distinguish between the influence of cell-to-cell variations, thermal gradients and cell connector design on the inhomogeneity of lithium-ion battery modules. As resistances for cell connectors and welding spot joints are considered for each single connection in the model (though the latter are not varied in this study), a possible irregularity during the battery module design or assembly can be examined and compared to the impact of assembling unmatched cells (in capacity or impedance) while discussing the influence of thermal gradients across the module. By using a p2D model for each cell, the arising inhomogeneity is discussed from an electrochemical point of view. 
The model coupling equations can be chosen from depicted flow charts for each of the connected cells and have been stated in detail which allows for a high reproducibility. The influence of different cell-to-cell variations on the inhomogeneity of lithium-ion battery modules is demonstrated for a $2 \mathrm{P}$ module under a $\mathrm{CC}-\mathrm{DCH}$ operation regime at $1 C$. From the results, implications for assembling battery modules are derived.

For homogeneous parallel connected cells, a symmetric design of cell connectors results in a symmetric current distribution whereas an asymmetric design results in asymmetric currents due to the resistances of the cell connectors. If cells under cell-to-cell variations are assembled in parallel, the current distribution between the strings depends on the ratio of the respective sum of the cell's OCV, the cell's internal polarization and the external polarization due to the cell connector design. An asymmetric design of cell connectors can have a much larger impact on an inhomogeneous current distribution within a battery module than cell-to-cell parametric variations do. The extent of this impact depends on the resistances of the assembled cell connectors and on the assembled cell-to-cell variations.

In order to reduce the occurring peak currents within an asymmetrically contacted module by cell matching, the cell with a higher capacity or higher impedance should be assembled close to the ST. In case thermal gradients are to be expected across the module, the ST should be exposed to the lower ambient temperature. This is valid for any chosen cell connectors. These withdrawn implications for matching of two parallel connected cells can be transferred to parallel connected battery modules and are therefore valuable regarding second life applications of battery modules.

Depending on the desired field of application of the battery module, our developed model can also be used to examine other optimization scenarios regarding cell matching. Analyzing the module inhomogeneity under dynamic operation and under cyclic aging as well as validating the model is subject to future investigations.

\section{Acknowledgment}

This work was financially supported by the Bavarian Ministry of Economy, Media, Energy and Technology under the auspices of EEBatt and by the SPICY project, which is funded by the European Union's Horizon 2020 Program (H2020) under grant agreement number 653373 .

\section{Appendix}

Summary of the governing equations within the p2D Newman-model.-The governing equations within the p2D Newman-model (PCM) are summarized in Table AI.
Implemented analytical equations within the p2D Newman-model.-The equilibrium potentials for a $\mathrm{Li}_{\mathrm{x}} \mathrm{C}_{6}$ negative electrode $E_{\text {eq,neg }}$ (compare Equation $\mathrm{A} 1$ ) and a $\mathrm{Li}_{\mathrm{y}} \mathrm{FePO}_{4}$ positive electrode $E_{\text {eq.pos }}$ (compare Equation A2) have been approximated by Safari et al. ${ }^{73}$ depending on the stoichiometry of the negative $x$ and positive electrode $y$ :

$$
\begin{aligned}
E_{\text {eq, neg }}(x)= & 0.6379+0.5416 \exp (-305.5309 x) \\
& +0.044 \tanh \left(-\frac{x-0.1958}{0.1088}\right) \\
& -0.1978 \tanh \left(\frac{x-1.0571}{0.0854}\right) \\
& -0.6875 \tanh \left(\frac{x+0.0117}{0.0529}\right) \\
& -0.0175 \tanh \left(\frac{x-0.5692}{0.0875}\right) \\
E_{\text {eq,pos }}(y)=3.4323 & -0.8428 \exp \left(-80.2493(1-y)^{1.3198}\right) \\
- & 3.2474 \cdot 10^{-6} \exp \left(20.2645(1-y)^{3.8003}\right) \\
+ & 3.2482 \cdot 10^{-6} \exp \left(20.2646(1-y)^{3.7995}\right)
\end{aligned}
$$

The changes of the electrodes' equilibrium potentials with temperature $\frac{d E_{\mathrm{eq}}}{d T}$ influence the reversible heat generated in the cell during the electrochemical reaction. Therefore, the entropic heat coefficients are implemented in order to account for these changes. Guo et al. ${ }^{69}$ give an equation for the entropic coefficient of a $\mathrm{LiC}_{6}$-electrode (compare Equation A3). Li et al. ${ }^{74}$ have approximated entropy measurement data from Dodd ${ }^{75}$ for a $\mathrm{LiFePO}_{4}$-electrode (compare Equation A4). Both entropic coefficients are given in $\mathrm{mVK}^{-1}$.

$$
\begin{aligned}
\frac{d E_{\mathrm{eq}, \mathrm{neg}}(x)}{d T}= & (0.00527+3.29927 \cdot x \\
& -91.79326 \cdot x^{2}+1004.91101 \cdot x^{3} \\
& -5812.27813 \cdot x^{4}+19329.75490 \cdot x^{5} \\
& -37147.89470 \cdot x^{6}+38379.18127 \cdot x^{7} \\
& \left.-16515.05308 \cdot x^{8}\right) \cdot(1-48.09287 \cdot x \\
& +1017.23480 \cdot x^{2}-10481.80419 \cdot x^{3} \\
& +59431.30001 \cdot x^{4}-195881.64880 \cdot x^{5} \\
& +374577.31520 \cdot x^{6}-385821.16070 \cdot x^{7} \\
& \left.+165705.85970 \cdot x^{8}\right)^{-1}
\end{aligned}
$$

Table AI. Governing equations within the p2D Newman-model (PCM). $\mathrm{s}=$ solid phase, $\mathrm{l}=$ liquid phase.

Governing Equations

Section

Mathematical Expression

Boundary conditions

Kinetics

Butler-Volmer equation

Exchange current density

Electrode overpotential

S-1

s-1

S-1

$\mathrm{s}(r)$

$1(x)$

Ionic flux

Charge conservation s

Charge conservation 1

Mass balance

Species conservation s

Species conservation 1

$\mathrm{s}(r)$
$1(x)$

$$
\begin{gathered}
F_{\text {const }} i_{\mathrm{Li}}=j_{0}\left(\exp \left(\frac{\alpha_{\mathrm{a}} \eta_{\mathrm{CT}} F_{\text {const }}}{R_{\text {const }} T}\right)-\exp \left(-\frac{\alpha_{\mathrm{c}} \eta_{\mathrm{CT}} F_{\text {const }}}{R_{\text {const }} T}\right)\right) \\
j_{0}=F_{\text {const }} k_{\mathrm{s}, \text { pos }}^{\alpha_{\mathrm{a}}} k_{\mathrm{s}, \text { neg }}^{\alpha_{\mathrm{c}}}\left(c_{\mathrm{s}, \max }-c_{\mathrm{s}}\right)^{\alpha_{\mathrm{a}}}\left(c_{\mathrm{s}}\right)^{\alpha_{\mathrm{c}}}\left(\frac{c_{\mathrm{l}}}{c_{1, \text { ref }}}\right)^{\alpha_{\mathrm{a}}} \\
\eta_{\mathrm{CT}}=\phi_{\mathrm{s}}-\phi_{\mathrm{l}}-E_{\mathrm{eq}}
\end{gathered}
$$

$$
i_{\mathrm{s}}=-\sigma_{\mathrm{s}, \mathrm{eff}} \nabla \phi_{\mathrm{s}}
$$

$$
i_{1}=-\kappa_{\mathrm{l}, \mathrm{eff}} \nabla \phi_{\mathrm{l}}+\frac{2 \kappa_{1, \mathrm{eff}} R_{\text {const }} T}{F_{\text {const }}}\left(1+\frac{\partial \ln f_{ \pm}}{\partial \ln c_{1}}\right)\left(1-t_{+}\right) \nabla \ln c_{1}
$$

$$
\nabla i_{\mathrm{S}}-i_{\mathrm{Li}}=0
$$$$
\nabla i_{1}+i_{\mathrm{Li}}=0
$$

$$
\begin{gathered}
-\left.n \cdot i_{1}\right|_{x=0}=0 \\
-\left.n \cdot i_{1}\right|_{x=x_{\text {stack }}}=0
\end{gathered}
$$

$$
\frac{\partial c_{\mathrm{s}}}{\partial t}=D_{\mathrm{s}}\left(\frac{\partial^{2} c_{\mathrm{s}}}{\partial r^{2}}+\frac{2}{r} \frac{\partial c_{\mathrm{s}}}{\partial r}\right)
$$

$\varepsilon_{1} \frac{\partial c_{1}}{\partial t}=\nabla\left(D_{\mathrm{l}, \mathrm{eff}} \nabla c_{1}\right)+a_{\mathrm{v}} i_{\mathrm{Li}}\left(1-t_{+}\right)$ 


$$
\begin{aligned}
\frac{d E_{\text {eq,pos }}(y)}{d T}= & 1000 \cdot\left(-0.35376 y^{8}+1.3902 y^{7}\right. \\
& -2.2585 y^{6}+1.9635 y^{5}-0.98716 y^{4} \\
& +0.28857 y^{3}-0.046272 y^{2}+0.0032158 y \\
& \left.-1.9186 \cdot 10^{-5}\right)
\end{aligned}
$$

The transport properties of the electrolyte $D_{1}, \kappa_{1}$ and $\frac{\partial \ln f_{ \pm}}{\partial \ln c_{1}}$ are described in dependency of lithium concentration $c_{1}$ and cell temperature $T_{\text {cell }}$ according to Valøen et al. ${ }^{68}$ The electrolyte diffusivity $D_{1}\left(c_{1}, T_{\text {cell }}\right)$ is implemented as

$$
D_{1}\left(c_{1}, T_{\text {cell }}\right)=\left(10^{-4.43-\frac{54}{T_{\text {cell }}-229-5 \cdot c_{1}}-0.22 \cdot c_{1}}\right) \cdot 10^{-4}
$$

The electrolyte conductivity $\mathrm{k}_{\mathrm{l}}\left(c_{1}, T_{\text {cell }}\right)$ is described by

$$
\begin{aligned}
\kappa_{1}\left(c_{1}, T_{\text {cell }}\right)= & \frac{c_{1}}{10}\left(-10.5+0.074 T_{\text {cell }}-6.96 \cdot 10^{-5} T_{\text {cell }}^{2}\right. \\
& +0.668 c_{1}-0.0178 c_{1} T_{\text {cell }}+2.8 \cdot 10^{-5} c_{1} T_{\text {cell }}^{2} \\
& \left.+0.494 c_{1}^{2}-8.86 \cdot 10^{-4} c_{1}^{2} T_{\text {cell }}\right)^{2}
\end{aligned}
$$

The activity dependency $\frac{\partial \ln f_{ \pm}}{\partial \ln c_{1}}\left(c_{1}, T_{\text {cell }}\right)$ is given as

$$
\begin{aligned}
\frac{\partial \ln f_{ \pm}}{\partial \ln c_{1}}\left(c_{1}, T\right)= & \frac{1}{1-t_{+}}\left(0.601-0.24 c_{1}^{0.5}\right. \\
& \left.+0.982\left(1-0.0052\left(T_{\text {cell }}-298 \mathrm{~K}\right)\right) c_{1}^{1.5}\right)-1
\end{aligned}
$$

The diffusivity and reaction rate in the electrodes are assumed to follow a temperature dependent Arrhenius behavior according to Guo et al. ${ }^{69,70}$

The solid phase diffusivity $D_{\mathrm{s}}\left(T_{\text {cell }}\right)$ is implemented as

$$
D_{\mathrm{s}}\left(T_{\text {cell }}\right)=D_{\mathrm{s}, \text { ref }} \cdot \exp \left(-\frac{E_{\mathrm{a}, \mathrm{D}_{\mathrm{s}}}}{R_{\text {const }}}\left(\frac{1}{T_{\text {cell }}}-\frac{1}{T_{\text {ref }}}\right)\right)
$$

The reaction rate $k_{\mathrm{s}}\left(T_{\text {cell }}\right)$ is described by

$$
k_{\mathrm{s}}\left(T_{\text {cell }}\right)=k_{\text {ref }} \cdot \exp \left(-\frac{E_{\mathrm{a}, \mathrm{k}}}{R_{\text {const }}}\left(\frac{1}{T_{\text {cell }}}-\frac{1}{T_{\text {ref }}}\right)\right)
$$

Calculation of the convective heat transfer coefficient for a single cylindrical cell.The convective heat transfer coefficient $h_{\text {conv }}$ depends on dimensionless parameters such as Nusselt Nu, Reynolds Re and Prandtl Pr number as well as on the geometry of the overflown cell or bunch of cells respectively. The Nusselt number Nu relates the convective heat transfer coefficient $h_{\text {conv }}$ to the characteristic overflow length $L$ of the object and the thermal conductivity of the fluid $k_{\text {air }}{ }^{65}$ It thus defines the dimensionless heat transfer to an overflowing fluid. ${ }^{65}$

$$
\mathrm{Nu}=\frac{h_{\text {conv }} L}{k_{\text {air }}}
$$

The characteristic length $L$ of a cylindrical cell equals half the circumference of the cell, with $r_{\text {cell }}$ being the radius of the cell:

$$
L=\pi r_{\text {cell }}
$$

Gnielinski ${ }^{76}$ has defined the mean Nusselt number $\mathrm{Nu}_{\text {mean }}$ for perpendicular flow against cylinders:

$$
\mathrm{Nu}_{\text {mean }}=0.3+\sqrt{\mathrm{Nu}_{\mathrm{lam}}^{2}+\mathrm{Nu}_{\text {turb }}^{2}}
$$

$\mathrm{Nu}_{\text {lam }}$ and $\mathrm{Nu}_{\text {turb }}$ are the Nusselt numbers for laminar and turbulent flow, respectively.

$$
\begin{gathered}
\mathrm{Nu}_{\text {lam }}=0.664 \sqrt{\operatorname{Re}} \sqrt[3]{\operatorname{Pr}} \\
\mathrm{Nu}_{\text {turb }}=\frac{0.037 \operatorname{Re}^{0.8} \operatorname{Pr}}{1+2.443 \operatorname{Re}^{-0.1}\left(\operatorname{Pr}^{2 / 3}-1\right)}
\end{gathered}
$$

Re is the Reynolds number, Pr is the Prandtl number. Pr defines the ratio of the viscosity of the fluid $\nu$ to its temperature conductivity $\frac{k}{\varrho c_{\mathrm{p}}}$. It is a material value and relates the diffusive impulse transport to diffusive heat transport in friction afflicted fluids. ${ }^{65}$

$$
\operatorname{Pr}=\frac{\nu_{\text {air }} Q_{\text {air }} c_{\mathrm{p}, \text { air }}}{k_{\text {air }}}
$$

Re relates the inertia force to the friction force. It defines whether a flow stays laminar stable or becomes turbulent. ${ }^{64}$

$$
\operatorname{Re}=\frac{v_{\text {air }} L}{v_{\text {air }}}
$$

The equations for the Nusselt number are valid for the following ranges of Re and $\operatorname{Pr}:{ }^{64}$

$$
\begin{gathered}
10<\operatorname{Re}<10^{7} \\
0.6<\operatorname{Pr}<1000
\end{gathered}
$$

For a single cylindrical 26650 cell, $\mathrm{Re}=2553, \mathrm{Nu}_{\mathrm{lam}}=30$ and $\mathrm{Nu}_{\text {turb }}=18$ which results in $\mathrm{Nu}_{\text {mean }}=35$ and consequently $h_{\text {conv }}=22.5 \mathrm{Wm}^{-2} \mathrm{~K}^{-1}$ for $v_{\text {air }}=1 \mathrm{~ms}^{-1}$, $k_{\text {air }}=0.0259 \mathrm{Wm}^{-1} \mathrm{~K}, v_{\text {air }}=1.6 \times 10^{-5} \mathrm{~m}^{2} \mathrm{~s}^{-1}, \operatorname{Pr}=0.72$ and $T=25^{\circ} \mathrm{C}$.

\section{List of Symbols}

$a_{\mathrm{v}} \quad$ Active specific surface area $\left(\mathrm{m}^{-1}\right)$

$A_{\text {cell }} \quad$ Area of a cell exposed to the surrounding air $\left(\mathrm{m}^{2}\right)$

$A_{\text {cont }} \quad$ Area of the cell contacts $\left(\mathrm{m}^{2}\right)$

$A_{\text {elec }} \quad$ Area of the electrode $\left(\mathrm{m}^{2}\right)$

$\mathrm{Bi} \quad$ Biot number (no unit)

$c_{\mathrm{g}, \mathrm{th}} \quad$ Theoretical gravimetric capacity $\left(\mathrm{Ah} \mathrm{kg}^{-1}\right)$

$c_{1} \quad$ Concentration of lithium in the electrolyte $\left(\mathrm{mol} \mathrm{m}^{-3}\right)$

$c_{1,0} \quad$ Initial concentration of lithium in the electrolyte $\left(\mathrm{mol} \mathrm{m}^{-3}\right)$

$c_{\mathrm{p}} \quad$ Specific heat capacity $\left(\mathrm{Jkg}^{-1} \mathrm{~K}^{-1}\right)$

$c_{\mathrm{p} \text {,air }} \quad$ Specific heat capacity of air $\left(\mathrm{Jkg}^{-1} \mathrm{~K}^{-1}\right)$

$c_{\mathrm{p}, \text { cell }} \quad$ Specific heat capacity of a cell $\left(\mathrm{Jkg}^{-1} \mathrm{~K}^{-1}\right)$

$c_{\mathrm{p}, \mathrm{conn}} \quad$ Specific heat capacity of the cell connectors $\left(\mathrm{Jkg}^{-1} \mathrm{~K}^{-1}\right)$

$c_{\mathrm{s}} \quad$ Concentration of lithium in the active material $\left(\mathrm{mol} \mathrm{m}^{-3}\right)$

$c_{\mathrm{s}, 0} \quad$ Initial concentration of lithium in the active material $\left(\mathrm{mol} \mathrm{m}^{-3}\right)$

$c_{\mathrm{s}, \max } \quad$ Theoretical maximum concentration of lithium in the active material $\left(\mathrm{mol} \mathrm{m}^{-3}\right)$

$c_{\mathrm{v}, \mathrm{th}} \quad$ Theoretical volumetric capacity $\left(\mathrm{Ah} \mathrm{m}^{-3}\right)$

$C \quad$ Capacity of the cell (Ah)

$C_{\text {neg }}$

$C_{\text {nom }}$

$C_{\text {pos }}$

$d x_{\text {cell }}$

$D_{1}$

$D_{\mathrm{s}}$

$E_{\mathrm{a}, \mathrm{D}_{\mathrm{s}}}$

$E_{\mathrm{a}, \mathrm{k}}$

$E_{\text {eq }}$

$E_{\text {eq,neg }}$

$E_{\text {eq,pos }}$

$h_{\text {cell }}$

$h_{\text {conv }}$

$i_{\text {app }}$

$i_{\text {cell }}$

$i_{j}$

$i_{\mathrm{n}}$

Capacity of the negative electrode (Ah)

Nominal capacity of the cell $(\mathrm{Ah})$

Capacity of the positive electrode (Ah)

Distance between two adjacent connected cells (m)

Diffusion coefficient in the liquid phase $\left(\mathrm{m}^{2} \mathrm{~s}^{-1}\right)$

Diffusion coefficient in the solid phase $\left(\mathrm{m}^{2} \mathrm{~s}^{-1}\right)$

Activation energy for diffusion $\left(\mathrm{Jmol}^{-1}\right)$

Activation energy for reaction $\left(\mathrm{Jmol}^{-1}\right)$

Open circuit (equilibrium) potential (V)

Open circuit potential of the negative electrode $(\mathrm{V})$

Open circuit potential of the positive electrode (V)

Height of the cell (m)

Convective heat transfer coefficient $\left(\mathrm{Wm}^{-2} \mathrm{~K}^{-1}\right)$

Current applied at the system terminal (A)

Current flowing through a cell (A)

String current within string $j$ with $j \in[1, y]$ (A)

Current at the negative end of a string of $x$ serial connected cells (A)

$i_{\mathrm{n}, \mathrm{cell}} \quad$ Current at the negative cell pole (A)

$i_{\mathrm{p}} \quad$ Current at the positive end of a string of $x$ serial connected cells (A)

$i_{\mathrm{p}, \text { cell }} \quad$ Current at the positive cell pole (A)

$i_{\mathrm{v}} \quad$ Local current source $\left(\mathrm{Am}^{-3}\right)$

$j_{0} \quad$ Exchange current density $\left(\mathrm{Am}^{-2}\right)$

$j_{1 C} \quad$ Current density at a $C$-Rate $=1\left(\mathrm{Am}^{-2}\right)$

$j_{\text {loc }} \quad$ Local current density $\left(\mathrm{Am}^{-2}\right)$

$j_{\text {ns }} \quad$ Normal electrode current density $\left(\mathrm{Am}^{-2}\right)$

$j_{\text {rate }} \quad$ Current density at a given $C$-Rate $\left(\mathrm{Am}^{-2}\right)$

$k_{\text {air }}$

$k_{\text {conn }}$

Thermal conductivity of air $\left(\mathrm{Wm}^{-1} \mathrm{~K}^{-1}\right)$

Thermal conductivity of the cell connectors $\left(\mathrm{Wm}^{-1} \mathrm{~K}^{-1}\right)$

$k_{\text {ref }} \quad$ Reaction rate reference value $\left(\mathrm{ms}^{-1}\right)$

$k_{\mathrm{s}} \quad$ Reaction rate $\left(\mathrm{ms}^{-1}\right)$

$k_{\mathrm{r}} \quad$ Radial thermal conductivity of a cell $\left(\mathrm{Wm}^{-1} \mathrm{~K}^{-1}\right)$

$k_{\mathrm{z}} \quad$ Axial thermal conductivity of a cell $\left(\mathrm{Wm}^{-1} \mathrm{~K}^{-1}\right)$ 
Length of the cell connectors (m)

Mass of a cell $(\mathrm{kg})$

Molar mass of the active material $\left(\mathrm{gmol}^{-1}\right)$

Nusselt number (no unit)

Nusselt number for laminar flow (no unit)

Mean Nusselt number (no unit)

Nusselt number for turbulent flow (no unit)

Number of parallel connected strings in between of string $j$ and the ST (no unit)

Parallel connected cells in a battery module (no unit)

Prandtl number (no unit)

Heat (W)

Conducted heat $(\mathrm{W})$

Convected heat (W)

Dissipated heat (W)

Generated heat $(\mathrm{W})$

Radiated heat (W)

Heat averaged over the whole cell volume (W)

Radius of a cell (m)

Particle radius (m)

Electric resistance of a cell connector between serial connected cells $(\Omega)$

Internal resistance of the cell $(\Omega)$

Specific electric resistance of one current collector $\left(\Omega \mathrm{m}^{-1}\right)$

Reynolds number (no unit)

Effective impedance of the current collectors in a full cell $(\Omega)$

Resistance of the negative cell connector $(\Omega)$

Resistance of the positive cell connector $(\Omega)$

Thermal resistance per unit area of a spot-welded joint $\left(\mathrm{m}^{2} \mathrm{KW}^{-1}\right)$

Electric resistance of a spot-welded joint $(\Omega)$

Resistance of the welding spot at the negative cell pole $(\Omega)$

Resistance of the welding spot at the positive cell pole $(\Omega)$

Serial connected cells in a battery module (no unit)

Thickness of the cell connectors (m)

Thickness of the electrode $(\mathrm{m})$

Thickness of the current collector (m)

Thickness of the negative electrode (m)

Transport number (no unit)

Thickness of the positive electrode (m)

Thickness of the separator $(\mathrm{m})$

Temperature (K)

Ambient temperature (K)

Temperature of a cell (K)

Temperature at the center of a cell $(\mathrm{K})$

Temperature of a cell's contact area $(\mathrm{K})$

Temperature at the surface of a cell $(\mathrm{K})$

Velocity of air $\left(\mathrm{m} \mathrm{s}^{-1}\right)$

Width of the cell connectors (m)

Number of serial connected cells in a topology (no unit)

Electrode stoichiometry at delithiated state of a full cell (no unit)

Electrode stoichiometry at lithiated state of a full cell (no unit)

Length of an electrode stack (m)

Maximum x-coordinate of a PCM stack (m)

$\mathrm{x}$-coordinate of a PCM stack (m)

Length of the current collector (m)

Thickness of the cell contacts (m)

Number of parallel connected cells (or strings) in a topology (no unit)

Width of an electrode stack (m)

Width of the current collector (m)

$\mathrm{c}$

$\mathrm{s}$
Number of $\mathrm{e}-$ exchanged during (de-)lithiation (no unit)

\section{Greek}

$\alpha_{\mathrm{a}}$

$\alpha_{c}$

$\varepsilon_{1}$

$\varepsilon_{\mathrm{rad}}$

$\varepsilon_{\mathrm{s}}$

$\eta_{\mathrm{CT}}$

$\eta_{i}$

$\kappa_{1}$

$\mu$

$\nu_{\text {air }}$

$\phi$

$\phi_{1}$

$\phi_{\mathrm{s}}$

$\phi_{\text {sys }}$

Qair

QAM

@coll

@conn

$\sigma$

$\sigma_{\text {conn }}$

$\sigma_{\mathrm{s}}$

$\tau$

\section{Natural Constants}

$F_{\text {const }}$

$R_{\text {const }}$

air

amb

cell

coll

conn

cont

elec

hold

1

lam

mean

$\mathrm{n}$

neg

$\mathrm{p}$

pos

sep

stack

string

sys

turb

ws

Anodic charge-transfer coefficient (no unit)

Cathodic charge-transfer coefficient (no unit)

Electrolyte volume fraction (no unit)

Surface emissivity (no unit)

Active material volume fraction (no unit)

Overpotential due to charge transfer $(\mathrm{V})$

Internal polarization of a cell $i(\mathrm{~V})$

Ionic conductivity in the electrolyte $\left(\mathrm{Sm}^{-1}\right)$

Mean of a normal distribution (no unit)

Viscosity of air $\left(\mathrm{m}^{2} \mathrm{~s}^{-1}\right)$

Electric potential of a cell (V)

Potential of the liquid phase within a PCM (V)

Potential of the solid phase within a PCM (V)

Electric potential of the system (V)

Density of air $\left(\mathrm{k} \mathrm{gm}^{-3}\right)$

Density of the active material $\left(\mathrm{k} \mathrm{gm}^{-3}\right)$

Resistivity of the current collector material $\left(\Omega \mathrm{mm}^{2} \mathrm{~m}^{-1}\right)$

Density of the cell connectors $\left(\mathrm{kgm}^{-3}\right)$

Standard deviation of a normal distribution (no unit)

Electric conductivity of the cell connectors $\left(\mathrm{S} \mathrm{m}^{-1}\right)$

Electric conductivity of the active material $\left(\mathrm{S} \mathrm{m}^{-1}\right)$

Tortuosity (no unit)

\section{Subscripts}

Active material

Anode

Air

Ambient environment

Cathode

Cell

Current collector

Cell connector

Cell contacts

Electrode

Module holder

Liquid phase

Laminar flow

Mean value

Negative cell pole or negative end of a string

Negative electrode

Positive cell pole or positive end of a string

Positive electrode

Solid phase

Separator

Stack of anode, separator and cathode

String of multiple serial connected cells

System of multiple connected cells

Turbulent flow

Welding spot 


\section{ORCID}

Katharina Rumpf (D https://orcid.org/0000-0002-1382-5453

Alexander Rheinfeld (10 https://orcid.org/0000-0003-0995-7266

\section{References}

1. M. Dubarry, C. Truchot, M. Cugnet, B. Y. Liaw, K. Gering, S. Sazhin, D. Jamison, and C. Michelbacher, Evaluation of commercial lithium-ion cells based on composite positive electrode for plug-in hybrid electric vehicle applications. Part I: Initial characterizations, Journal of Power Sources, 196, 10328 (2011).

2. S. Paul, C. Diegelmann, H. Kabza, and W. Tillmetz, Analysis of aging inhomogeneities in lithium-ion battery systems, Journal of Power Sources, 239, 642 (2013).

3. S. F. Schuster, M. J. Brand, P. Berg, M. Gleissenberger, and A. Jossen, Lithiumion cell-to-cell variation during battery electric vehicle operation, Journal of Power Sources, 297, 242 (2015).

4. C. Campestrini, P. Keil, S. F. Schuster, and A. Jossen, Ageing of lithium-ion battery modules with dissipative balancing compared with single-cell aging, Journal of Energy Storage, 6, 142 (2016).

5. K. Rumpf, M. Naumann, and A. Jossen, Experimental investigation of parametric cell-to-cell variation and correlation based on 1100 commercial lithium-ion cells, Journal of Energy Storage, 14, 224 (2017)

6. S. Miyatake, Y. Susuki, T. Hikihara, S. Itoh, and K. Tanaka, Discharge characteristics of multicell lithium-ion battery with nonuniform cells, Journal of Power Sources, 241, 736 (2013)

7. R. Gogoana, M. Pinson, M. Bazant, and S. Sarma, Internal resistance matching for parallel-connected lithium-ion cells and impacts on battery pack cycle life, Journal of Power Sources, 252, 8 (2014).

8. M. J. Brand, M. H. Hofmann, M. Steinhardt, S. F. Schuster, and A. Jossen, Current distribution within parallel-connected battery cells, Journal of Power Sources, 334, 202 (2016).

9. T. Bruen and J. Marco, Modelling and experimental evaluation of parallel connected lithium ion cells for an electric vehicle battery system, Journal of Power Sources, 310, 91 (2016).

10. F. An, J. Huang, C. Wang, Z. Li, J. Zhang, S. Wang, and P. Li, Cell sorting for parallel lithium-ion battery systems: Evaluation based on an electric circuit model, Journal of Energy Storage, 6, 195 (2016).

11. C. Pastor-Fernandez, T. Bruen, W. D. Widanage, M. A. Gama-Valdez, and J. Marco, A Study of Cell-to-Cell Interactions and Degradation in Parallel Strings: Implications for the Battery Management System, Journal of Power Sources, 329, 574 (2016).

12. M. Dubarry, N. Vuillaume, and B. Y. Liaw, Origins and accommodation of cell variations in Li-ion battery pack modeling, International Journal of Energy Research, 34, 216 (2010).

13. N. Ganesan, S. Basu, K. S. Hariharan, S. M. Kolake, T. Song, T. Yeo, D. K. Sohn, and S. Doo, Physics based modeling of a series parallel battery pack for asymmetry analysis, predictive control and life extension, Journal of Power Sources, 322, 57 (2016).

14. L. Wang, Y. Cheng, and X. Zhao, Influence of connecting plate resistance upon LiFePO4 battery performance, Applied Energy, 147, 353 (2015).

15. G. J. Offer, V. Yufit, D. A. Howey, B. Wu, and N. P. Brandon, Module design and fault diagnosis in electric vehicle batteries, Journal of Power Sources, 206, 383 (2012).

16. B. Wu, V. Yufit, M. Marinescu, G. J. Offer, R. F. Martinez-Botas, and N. P. Brandon, Coupled thermal-electrochemical modeling of uneven heat generation in lithium-ion battery packs, Journal of Power Sources, 243, 544 (2013).

17. T. Wang, K. J. Tseng, J. Zhao, and Z. Wei, Thermal investigation of lithium-ion battery module with different cell arrangement structures and forced air-cooling strategies, Applied Energy, 134, 229 (2014).

18. K.-C. Chiu, C.-H. Lin, S.-F. Yeh, Y.-H. Lin, C.-S. Huang, and K.-C. Chen, Cycle life analysis of series connected lithium-ion batteries with temperature difference, Journal of Power Sources, 263, 75 (2014).

19. N. Yang, X. Zhang, B. Shang, and G. Li, Unbalanced discharging and aging due to temperature differences among the cells in a lithium-ion battery pack with parallel combination, Journal of Power Sources, 306, 733 (2016)

20. T. Waldmann, B.-I. Hogg, and M. Wohlfahrt-Mehrens, Li plating as unwanted side reaction in commercial Li-ion cells - A review, Journal of Power Sources, 384, 107 (2018).

21. F. Altaf, L. Johannesson, and B. Egardt, Simultaneous Thermal and State-of-Charge Balancing of Batteries: A Review. Proceedings IEEE Vehicle Power and Propulsion Conference (VPPC, Coimbra, Portugal, 2014), 2014.

22. J. V. Barreras, C. Pinto, R. de Castro, E. Schaltz, S. J. Andreasen, and R. E. Araujo, Multi-Objective Control of Balancing Systems for Li-Ion Battery Packs: A Paradigm Shift, Proceedings IEEE Vehicle Power and Propulsion Conference (VPPC, Coimbra, Portugal, 2014) 2014.

23. C. Pinto, J. V. Barreras, E. Schaltz, and R. E. Araujo, Evaluation of Advanced Control for Li-ion Battery Balancing Systems using Convex Optimization. IEEE Transactions on Sustainable Energy, 7, 1703 (2016).

24. J. Kim and B. H. Cho, Screening process-based modeling of the multi-cell battery string in series and parallel connections for high accuracy state-of-charge estimation, Energy, 57, 581 (2013).

25. S. Kamalisiahroudi, J. Huang, Z. Li, and J. Zhang, Study of Temperature Difference and Current Distribution in Parallel-Connected Cells at Low Temperature, International Journal of Electrical, Robotics, Electronics and Communications Engineering, 8, 1589 (2014)
26. T. Grün, K. Stella, and O. Wollersheim, Impacts on load distribution and aging in Lithium-ion home storage systems, Energy Procedia, 135, 236 (2017).

27. M. Fleckenstein, O. Bohlen, M. A. Roscher, and B. Bäker, Current density and state of charge inhomogeneities in Li-ion battery cells with $\mathrm{LiFePO}_{4}$ as cathode material due to temperature gradients, Journal of Power Sources, 196, 4769 (2011).

28. O. Capron, A. Samba, N. Omar, T. Coosemans, P. Van den Bosche, and J. Van Mierlo, Lithium-Ion Batteries: Thermal Behaviour Investigation of Unbalanced Modules, Sustainability, 7, 8374 (2015).

29. M. Dubarry, A. Devie, and B. Y. Liaw, Cell-balancing currents in parallel strings of a battery system, Journal of Power Sources, 321, 36 (2016).

30. Y. Troxler, B. Wu, M. Marinescu, V. Yufit, Y. Patel, A. J. Marquis, N. P. Brandon, and G. J. Offer, The effect of thermal gradients on the performance of lithium-ion batteries, Journal of Power Sources, 247, 1018 (2014).

31. W. Shi, X. Hu, C. Jin, J. Jiang, Y. Zhang, and T. Yip, Effects of imbalanced currents on large-format LiFePO4-graphite batteries systems connected in parallel, Journal of Power Sources, 2016, 198 (2016).

32. H.-H. Huang, H.-Y. Chen, K.-C. Liao, H.-T. Young, H.-T. Lee, and J.-Y. Tien, Thermal electrochemical coupled simulations for cell-to-cell imbalances in lithiumiron-phosphate based battery packs, Applied Thermal Engineering, 123, 584 (2017).

33. M. P. Klein and J. W. Park, Current Distribution Measurements in Parallel-Connected Lithium-Ion Cylindrical Cells under Non-Uniform Temperature Conditions. Journal of The Electrochemical Society, 164, A1893 (2017).

34. M. Doyle, T. F. Fuller, and J. Newman, Modeling of Galvanostatic Charge and Discharge of the Lithium/Polymer/Insertion Cell, Journal of The Electrochemical Society, 140, 1526 (1993).

35. M. Doyle and J. Newman, Comparison of Modeling Predictions with Experimental Data from Plastic Lithium Ion Cells, Journal of The Electrochemical Society, 143, 1890 (1995)

36. T. F. Fuller, M. Doyle, and J. Newman, Simulation and Optimization of the Dual Lithium Ion Insertion Cell, Journal of The Electrochemical Society, 141, 1 (1994).

37. J. Newman and K. Thomas-Alyea, Electrochemical Systems, John Wiley \& Sons Inc.: Hoboken, New Jersey, 2004.

38. S. Rothgang, T. BaumhÃüfer, H. van Hoek, T. Lange, R. W. De Doncker, and D. U. Sauer, Modular battery design for reliable, flexible and multi-technology energy storage systems, Applied Energy, 137, 931 (2015).

39. J. Kasnatscheew, T. Placke, B. Streipert, S. Rothermel, R. Wagner, P. Meister, I. C. Laskovic, and M. Winter, A Tutorial into Practical Capacity and Mass Balancing of Lithium Ion Batteries, Journal of The Electrochemical Society, 164, A2479 (2017).

40. D. J. Docimo and H. K. Fathy, Multivariable State Feedback Control as a Foundation for Lithium-Ion Battery Pack Charge and Capacity Balancing, Journal of The Electrochemical Society, 164, A61 (2017).

41. J. Wilhelm, S. Seidlmayer, P. Keil, J. Schuster, A. Kriele, R. Gilles, and A. Jossen, Cycling capacity recovery effect: A coulombic efficiency and postmortem study, Journal of Power Sources, 365, 327 (2017).

42. M. Doyle, J. P. Meyers, and J. Newman, Computer Simulations of the Impedance Response of Lithium Rechargeable Batteries, Journal of The Electrochemical Society, 147, 99 (2000)

43. J. P. Meyers, M. Doyle, R. M. Darling, and J. Newman, The Impedance Response of a Porous Electrode Composed of Intercalation Particles, Journal of The Electrochemical Society, 147, 2930 (2000).

44. J. Huang, H. Ge, Z. Li, and J. Zhang, An Agglomerate Model for the Impedance of Secondary Particle in Lithium-Ion Battery Electrode, Journal of The Electrochemical Society, 161, E3202 (2014)

45. G. Sikha and R. E. White, Analytical Expression for the Impedance Response of an Insertion Electrode Cell, Journal of The Electrochemical Society, 154, A43 (2007).

46. G. Sikha and R. E. White, Analytical Expression for the Impedance Response for a Lithium-Ion Cell, Journal of The Electrochemical Society, 155, A893 (2008).

47. A. Nyman, T. G. Zavalis, R. Elger, M. Behm, and G. Lindbergh, Analysis of the Polarization in a Li-Ion Battery Cell by Numerical Simulations, Journal of The Electrochemical Society, 157, A1236 (2010).

48. R. Chandrasekaran, Quantification of contributions to the cell overpotential during galvanostatic discharge of a lithium-ion cell, Journal of Power Sources, 262, 501 (2014).

49. J. Huang, Z. Li, J. Zhang, S. Song, Z. Lou, and N. Wu, An Analytical Three-Scale Impedance Model for Porous Electrode with Agglomerates in Lithium-Ion Batteries, Journal of The Electrochemical Society, 162, A585 (2015)

50. J. N. Reimers, Accurate and Efficient Treatment of Foil Currents in a Spiral Wound Li-Ion Cell, Journal of The Electrochemical Society, 161, A118 (2014).

51. L. Fahrmeir, C. Heumann, R. Künstler, I. Pigeot, and G. Tutz, Statistik, 8th ed. Springer: Berlin Heidelberg, 2016

52. A. A. Pesaran, Battery thermal models for hybrid vehicle simulations, Journal of Power Sources, 110, 377 (2002)

53. R. Korthauer, Handbuch Lithium-Ionen-Batterien; Springer: Berlin Heidelberg, 2013.

54. S. V. Erhard, P. J. Osswald, J. Wilhelm, A. J. Rheinfeld, S. Kosch, and A. Jossen, Simulation and Measurement of Local Potentials of Modified Commercial Cylindrical Cells, II: Multi-Dimensional Modeling and Validation, Journal of The Electrochemical Society, 162, A2707 (2015).

55. A. Rheinfeld, S. Kosch, S. V. Erhard, P. J. Osswald, B. Rieger, and A. Jossen, ElectroThermal Modeling of Large Format Lithium-Ion Pouch Cells: A Cell Temperature Dependent Linear Polarization Expression, Journal of The Electrochemical Society, 163, A3046 (2016).

56. S. V. Erhard, Mehrdimensionale elektrochemisch-thermische Modellierung von Lithium-Ionen-Batterien. Dissertation, Technical University of Munich, Department 
of Electrical and Computer Engineering, Institute for Electrical Energy Storage Technology, Munich, Germany, 2017.

57. S. V. Erhard et al., Simulation and Measurement of the Current Density Distribution in Lithium-Ion Batteries by a Multi-Tab Cell Approach, Journal of The Electrochemical Society, 164, A6324 (2017).

58. S. Kosch, A. Rheinfeld, S. V. Erhard, and A. Jossen, An extended polarization model to study the influence of current collector geometry of large-format lithium-ion pouch cells, Journal of Power Sources, 342, 666 (2017).

59. T. Bandhauer, S. Garimella, and T. F. Fuller, Electrochemical-Thermal Modeling to Evaluate Battery Thermal Management Strategies: I. Side Cooling, Journal of The Electrochemical Society, 162, A125 (2015).

60. H. Bernardi, E. Pawlikowski, and J. Newman, A General Energy Balance for Battery Systems, Journal of The Electrochemical Society, 132, 5 (1985)

61. S. C. Chen, C. C. Wan, and Y. Y. Wang, Thermal analysis of lithium-ion batteries, Journal of Power Sources, 140, 111 (2005).

62. T. Bandhauer, S. Garimella, and T. F. Fuller, A Critical Review of Thermal Issues in Lithium-Ion Batteries, Journal of The Electrochemical Society, 158, R1 (2011).

63. S. Drake, D. Wetz, J. Ostanek, S. Miller, J. Heinzel, and A. Jain, Measurement of anisotropic thermophysical properties of cylindrical Li-ion cells, Journal of Power Sources, 252, 298 (2014).

64. VDI e.V., VDI-Wärmeatlas, 11th ed.; Springer: Berlin Heidelberg, 2013.

65. W. Polifke and J. Kopitz, Wärmeübertragung - Grundlagen, analytische und numerische Methoden, 2nd ed.; Pearson Studium: München, 2009.

66. G. Zhang, L. Cao, S. Ge, C.-Y. Wang, C. E. Shaffer, and C. D. Rahn, In Situ Measurement of Radial Temperature Distributions in Cylindrical Li-Ion Cells. Journal of The Electrochemical Society, 161, A1499 (2014).

67. TATA Steel,; HILUMIN Batterie-Verbinderband. 15.01.2017; https://www.tatasteeleurope.com/en/products-and-services/flat/electro-plated/ hilumin/hilumin.

68. L. O. Valøen and J. N. Reimers, Transport Properties of LiPF6-Based Li-Ion Battery Electrolytes, Journal of The Electrochemical Society, 152, A882 (2005).

69. M. Guo, G. Sikha, and R. E. White, Single-Particle Model for a Lithium-Ion Cell: Thermal Behavior, Journal of The Electrochemical Society, 158, A122 (2011)
70. M. Guo and R. White, A distributed thermal model for a Li-ion electrode plate pair, Journal of Power Sources, 221, 334 (2013).

71. H. Maleki, S. Al Hallaj, J. R. Selman, R. B. Dinwiddie, and H. Wang, Therma Properties of Lithium-Ion Battery and Components, Journal of The Electrochemical Society, 146, 947 (1999).

72. G. Guo, B. Long, B. Cheng, S. Zhou, P. Xu, and B. Cao, Three-dimensional thermal finite element modeling of lithium-ion battery in thermal abuse application, Journal of Power Sources, 195, 2393 (2010).

73. M. Safari and C. Delacourt, Modeling of a Commercial Graphite/LiFePO Cell, Journal of The Electrochemical Society, 158, A562 (2011).

74. J. Li, Y. Cheng, M. Jia, Y. Tang, Y. Lin, Z. Zhang, and Y. Liu, An electrochemicalthermal model based on dynamic responses for lithium iron phosphate battery, Journal of Power Sources, 255, 130 (2014).

75. J. L. Dodd, Phase composition and dynamical studies of lithium iron phosphate. Dissertation, California Institute of Technology, Engineering and Applied Science, Pasadena, California, 2007.

76. V. Gnielinski, Berechnung mittlerer Wärme- und Stoffübergangskoeffizienten an laminar und turbulent überströmten Einzelkörpern mit Hilfe einer einheitlichen Gleichung, Forschung im Ingenieurwesen, 41, 145 (1975).

77. J. Landesfeind, J. Hattendorff, A. Ehrl, W. A. Wall, and H. A. Gasteiger, Tortuosity Determination of Battery Electrodes and Separators by Impedance Spectroscopy, Journal of The Electrochemical Society, 163, A1373 (2016).

78. M. Doyle and J. Newman, Comparison of Modeling Predictions with Experimenta Data from Plastic Lithium Ion Cells, Journal of The Electrochemical Society, 143, 1890 (1996).

79. M. Doyle and Y. Fuentes, Computer Simulations of a Lithium-Ion Polymer Battery and Implications for Higher Capacity Next-Generation Battery Designs, Journal of The Electrochemical Society, 150, A706 (2003).

80. S.-Y. Chung, J. T. Bloking, and Y.-M. Chiang, Electronically conductive phosphoolivines as lithium storage electrodes, Nature Materials, 1, A123 (2002).

81. M. J. Brand, P. A. Schmidt, M. F. Zäh, and A. Jossen, Welding techniques for battery cells and resulting electrical contact resistances, Journal of Energy Storage, 1, 7 (2015).

82. R. P. Tye, Thermal Conductivity, 2nd ed.; Academic Press: London and New York, 1969. 